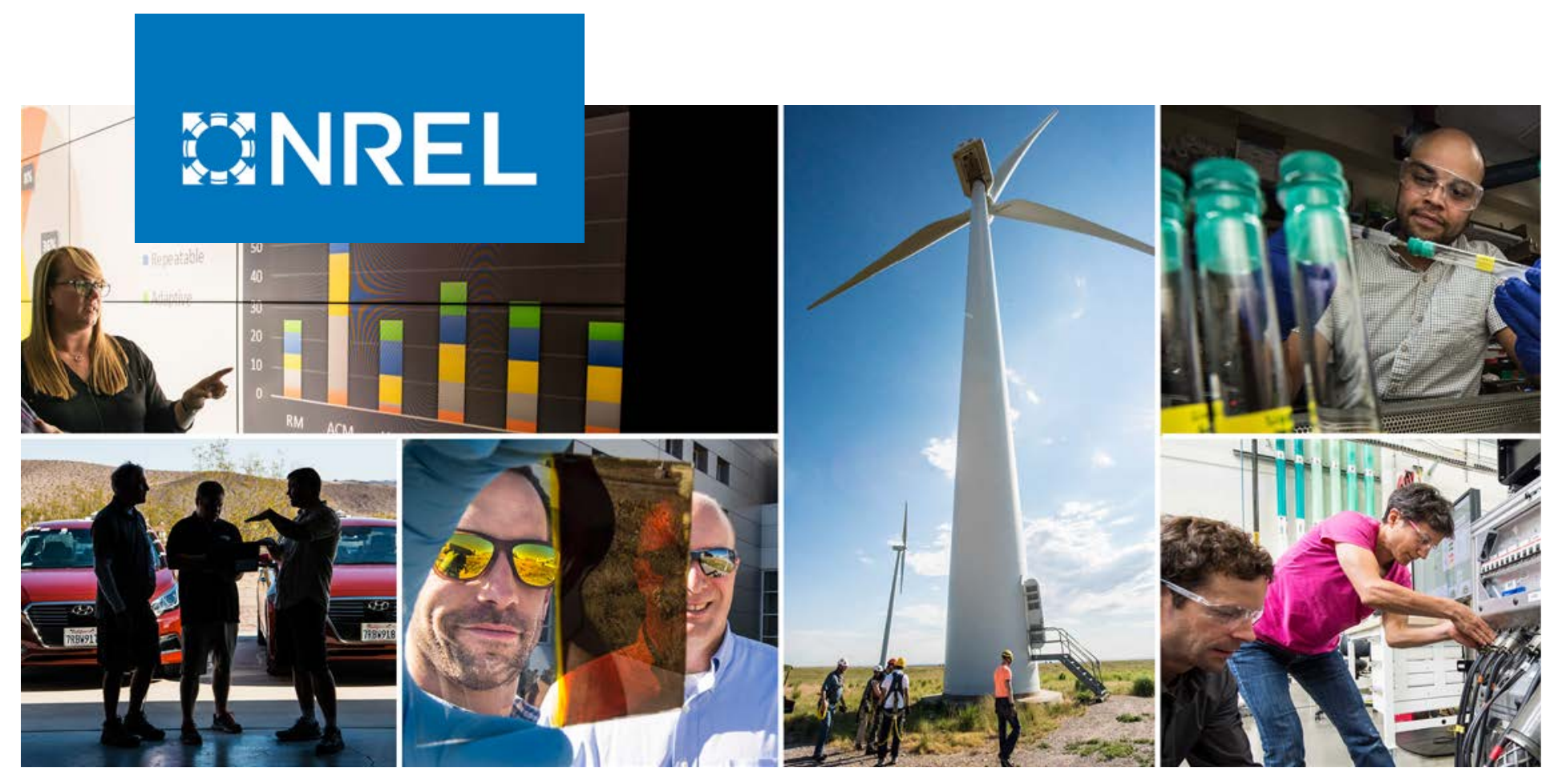

\title{
A Detailed Wind Turbine Blade Cost Model
}

P. Bortolotti, D. Berry, R. Murray, E. Gaertner, D. Jenne,

R. Damiani, G. Barter, and K. Dykes

National Renewable Energy Laboratory

NREL is a national laboratory of the U.S. Department of Energy Office of Energy Efficiency \& Renewable Energy

Operated by the Alliance for Sustainable Energy, LLC

This report is available at no cost from the National Renewable Energy Laboratory (NREL) at www.nrel.gov/publications.
Technical Report

NREL/TP-5000-73585

June 2019 


\section{GNREL}

\section{A Detailed Wind Turbine Blade Cost Model}

P. Bortolotti, D. Berry, R. Murray, E. Gaertner, D. Jenne, R. Damiani, G. Barter, and K. Dykes

National Renewable Energy Laboratory

\section{Suggested Citation}

Bortolotti, P., D. Berry, R. Murray, E. Gaertner, D. Jenne, R. Damiani, G. Barter, K. Dykes. 2019. A Detailed Wind Turbine Blade Cost Model. Golden, CO: National Renewable Energy Laboratory. NREL/TP-5000-73585. https://www.nrel.gov/docs/fy19osti/73585.pdf.

NREL is a national laboratory of the U.S. Department of Energy Office of Energy Efficiency \& Renewable Energy Operated by the Alliance for Sustainable Energy, LLC

This report is available at no cost from the National Renewable Energy Laboratory (NREL) at www.nrel.gov/publications.

Contract No. DE-AC36-08GO28308
Technical Report NREL/TP-5000-73585 June 2019

National Renewable Energy Laboratory 15013 Denver West Parkway Golden, CO 80401 303-275-3000 • www.nrel.gov 


\section{NOTICE}

This work was authored by the National Renewable Energy Laboratory, operated by Alliance for Sustainable Energy, LLC, for the U.S. Department of Energy (DOE) under Contract No. DE-AC36-08G028308. Funding provided by U.S. Department of Energy Office of Energy Efficiency and Renewable Energy Wind Energy Technologies Office. The views expressed herein do not necessarily represent the views of the DOE or the U.S. Government.

This report is available at no cost from the National Renewable Energy Laboratory (NREL) at www.nrel.gov/publications.

U.S. Department of Energy (DOE) reports produced after 1991 and a growing number of pre-1991 documents are available free via www.OSTI.gov.

Cover Photos by Dennis Schroeder: (clockwise, left to right) NREL 51934, NREL 45897, NREL 42160, NREL 45891, NREL 48097, NREL 46526.

NREL prints on paper that contains recycled content. 


\section{Acknowledgments}

This work was sponsored by the U.S. Department of Energy through funding from multiple projects.

The authors would like to thank Josh Paquette, of Sandia National Laboratories, for providing the input files for the WindPACT and SNL-series 100-meter blades. Garrett Barter, of the National Renewable Energy Laboratory, for reviewing and greatly improving the report. Finally, Stephen Nolet, senior director at TPI Composites, and Stephen B. Johnson, adjunct professor at UMass Lowell, for providing useful feedback on the modeling assumptions throughout multiple rounds of review. 


\section{Executive Summary}

This technical report describes a detailed blade cost model for wind turbine blades in the range of 30 to 100 meters in length. The model estimates the bill of materials, the number of labor hours and the cycle time, and the costs related to direct labor, overhead, buildings, tooling, equipment, maintenance, and capital. The model applies to multimegawatt wind turbine blades manufactured via vacuum-assisted resin transfer molding, which is the most commonly adopted manufacturing method for modern wind turbine blades.

The model is implemented both in a large Excel file and in Python. The latter is freely available in the repository of the Wind-Plant Integrated System Design and Engineering Model (WISDEM $®$ ) github.com/WISDEM. WISDEM is a multidisciplinary analysis and optimization design framework developed at the National Renewable Energy Laboratory. This blade cost model represents a valuable tool to run design optimization studies for wind turbines.

In this report, the model is first presented with its approach and assumptions and then computes the costs of three blades, namely the 33-meter-long Wind Partnership for Advanced Component Technologies (WindPACT) study blade, the 63-meter-long International Energy Agency (IEA) Wind Task 37 land-based reference wind turbine blade, and the 100-meter-long SNL-100-03 blade developed at Sandia National Laboratories. 


\section{Acronym List}

$\begin{array}{ll}\text { Bx } & \text { Biaxial fabric } \\ \text { CF } & \text { Carbon fiber } \\ \text { CT } & \text { Cycle time } \\ \text { FVF } & \text { Fiber volume fraction } \\ \text { GF } & \text { Glass fiber } \\ \text { HP } & \text { High pressure } \\ \text { hr } & \text { Hour } \\ \text { in } & \text { Inch } \\ \text { kg } & \text { Kilogram } \\ \text { LE } & \text { Leading edge } \\ \text { LP } & \text { Low pressure } \\ \text { LPS } & \text { Lightning protection system } \\ \text { m } & \text { Meter } \\ \text { MDAO } & \text { Multidisciplinary design, analysis, and optimization } \\ \text { NREL } & \text { National Renewable Energy Laboratory } \\ \text { SC } & \text { Spar cap } \\ \text { SNL } & \text { Sandia National Laboratories } \\ \text { SW } & \text { Shear web } \\ \text { TE } & \text { Trailing edge } \\ \text { Tx } & \text { Triaxial fabric } \\ \text { VARTM } & \text { Vacuum-assisted resin transfer molding } \\ \text { UD } & \text { Unidirectional fabric }\end{array}$




\section{Table of Contents}

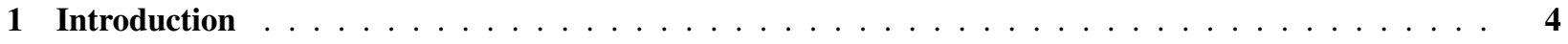

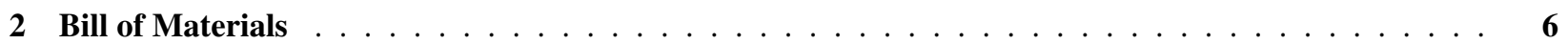

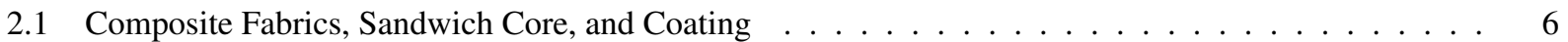

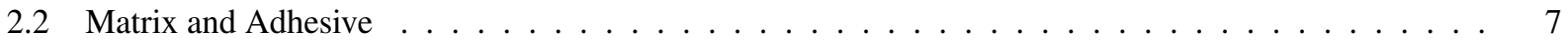

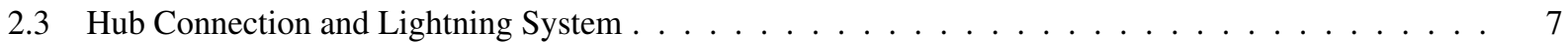

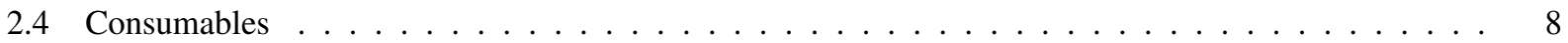

3 Labor and Cycle Times $\ldots \ldots \ldots \ldots \ldots \ldots$

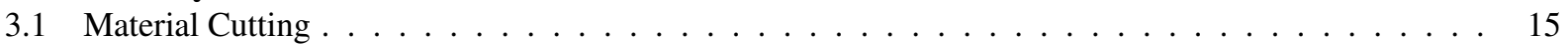

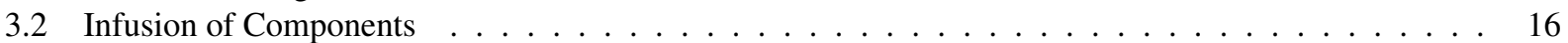

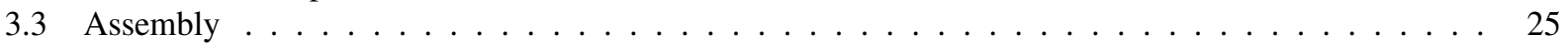

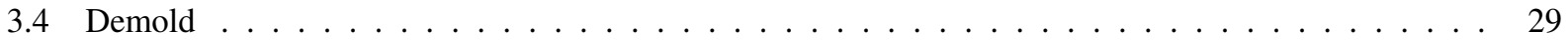

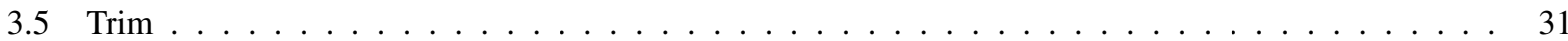

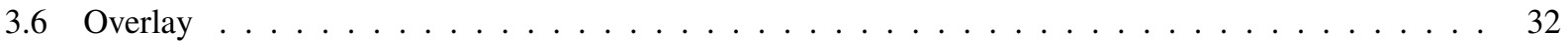

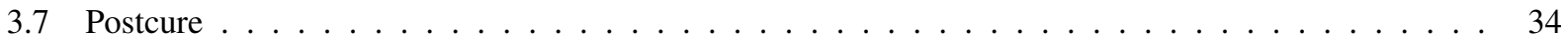

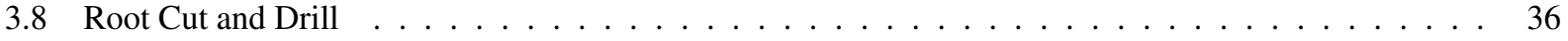

3.9 Root Fasteners Installation $\ldots \ldots \ldots \ldots$. . . . . . . . . . . . . . . . 37

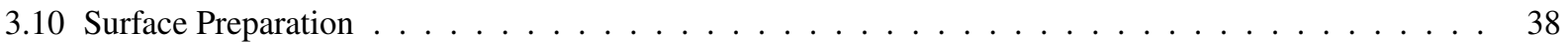

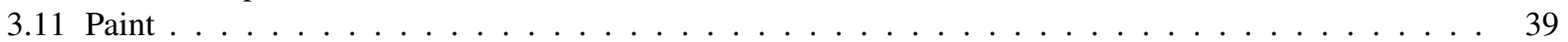

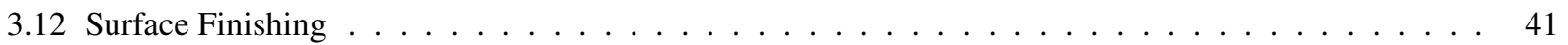

3.13 Weight and Balance . . . . . . . . . . . . . . . . . . . . . . . 41

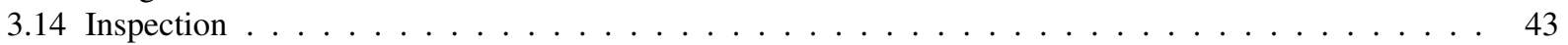

3.15 Shipping Preparation $\ldots \ldots \ldots \ldots \ldots \ldots \ldots \ldots \ldots$

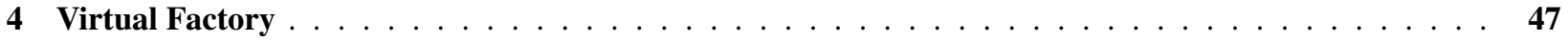

4.1 Direct Labor Costs . . . . . . . . . . . . . . . . . . . . . . . . . . . . . 48

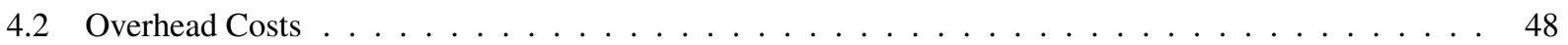

4.3 Building Costs $\ldots \ldots \ldots \ldots \ldots \ldots \ldots \ldots \ldots$

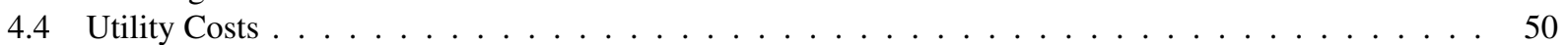

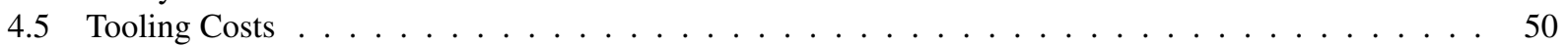

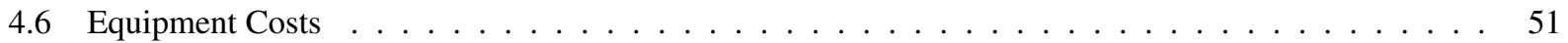

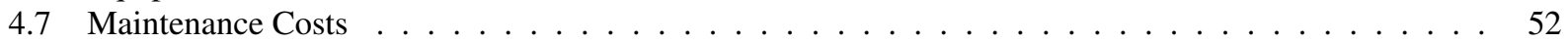

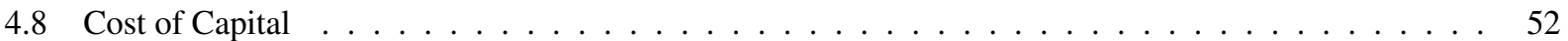

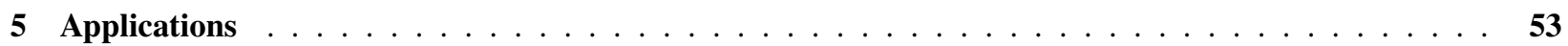

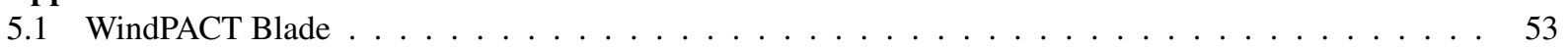

5.2 IEA Wind Task 37 Land-Based Reference Wind Turbine Blade . . . . . . . . . . . . . . . . . 56

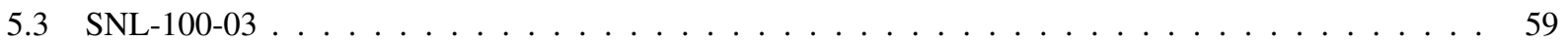

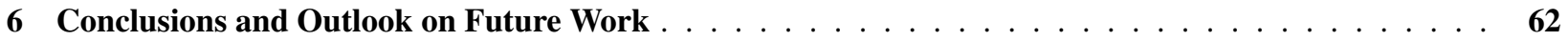




\section{List of Figures}

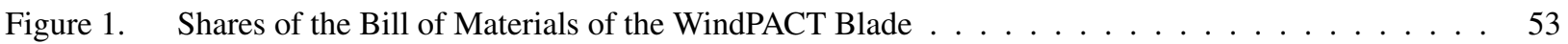

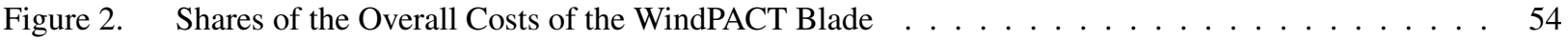

Figure 3. Shares of the Bill of Materials of the IEA Land-Based Reference Wind Turbine Blade . . . . . . . 56

Figure 4. Shares of the Overall Costs of the IEA Land-Based Reference Wind Turbine Blade . . . . . . . 58

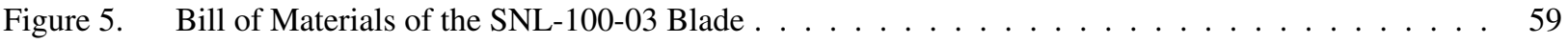

Figure 6. Shares of the Overall Costs of the SNL-100-03 Blade . . . . . . . . . . . . . . . . . . . 61

\section{List of Tables}

Table 1. Default Prices for Composite Fabrics, Sandwich Core, and Coating . . . . . . . . . . . 6

Table 2. Default Prices for Composite Matrix and Adhesive . . . . . . . . . . . . . . . . . 7

Table 3. Standard Inputs for Computing the Cost of the Peel-Ply $\ldots \ldots \ldots \ldots$

Table 4. Standard Inputs for Computing the Cost of the Nonsand Tape $\ldots \ldots \ldots \ldots$

Table 5. Standard Inputs for Computing the Cost of the Chopped Strand . . . . . . . . . . . . . . . 9

Table 6. Standard Inputs for Computing the Cost of the Tackifier Adhesive . . . . . . . . . . . . . . . 9

Table 7. Standard Inputs for Computing the Cost of the Release Agent $\ldots \ldots \ldots \ldots$

Table 8. Standard Inputs for Computing the Cost of the Flow Medium . . . . . . . . . . . . . . . . 10

Table 9. Standard Inputs for Computing the Cost of the Tubing . . . . . . . . . . . . . . . . . 11

Table 10. Standard Inputs for Computing the Cost of Tacky Tape . . . . . . . . . . . . . . . . . . 11

Table 11. Standard Inputs for Computing the Cost of the Masking Tape $\ldots \ldots \ldots$. . . . . . . . . . 12

Table 12. Standard Inputs for Computing the Cost of the Chop Fiber . . . . . . . . . . . . . . . . . . 12

Table 13. Standard Inputs for Computing the Cost of White Lightning Protection . . . . . . . . . . . . 12

Table 14. Standard Inputs for Computing the Cost of the Hardener ～. . . . . . . . . . . . . . . . 13

Table 15. Standard Inputs for Computing the Cost of the Putty . . . . . . . . . . . . . . . . . . . 13

Table 16. Standard Inputs for Computing the Cost of the Putty Catalyst $\ldots \ldots \ldots \ldots$

Table 17. Layup Rates and Number of Workers for the Fabric Layup . . . . . . . . . . . . . . . . . . 18

Table 18. Coefficients of the Regression Polynomials to Estimate the Infusion Cycle Time, Measured in

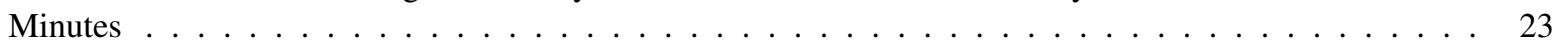

Table 19. Lengths $L_{1}$ and $L_{2}$ Used to Compute the Floor Space Needed in each Operation $\ldots \ldots$ 
Table 20. Default Values of Equipment Cost per Length and Scaling Length, $L$, to Estimate the Total Equip-

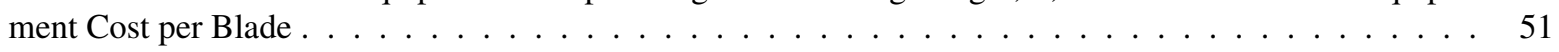

Table 21. Bill of Materials of the WindPACT Blade . . . . . . . . . . . . . . . . . . . . 54

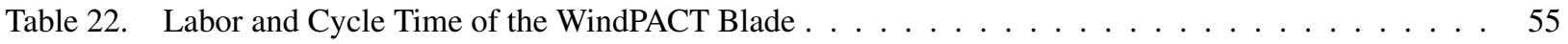

Table 23. Total Costs of the WindPACT Blade . . . . . . . . . . . . . . . . . . . . . . 55

Table 24. Total Composite, Core, and Coating Costs of the IEA Land-Based Reference Wind Turbine Blade . 56

Table 25. Labor and Cycle Time of the IEA Land-Based Reference Wind Turbine Blade . . . . . . . . . 57

Table 26. Total Costs of the IEA Land-Based Reference Wind Turbine Blade ～. . . . . . . . . . . . . . 58

Table 27. Total Composite, Core, and Coating Costs of the SNL-100-03 Blade . . . . . . . . . . . . . 59

Table 28. Labor and Cycle Time of the SNL-100-03 Blade . . . . . . . . . . . . . . . . . . . . 60

Table 29. Total Costs of the SNL-100-03 Blade $\ldots \ldots \ldots \ldots \ldots \ldots$ 


\section{Introduction}

This work aims to define a detailed parametric blade cost model for modern multimegawatt wind turbine blades via vacuum-assisted resin transfer molding (VARTM). VARTM is the most commonly adopted manufacturing method for modern blades. The model estimates variable and fixed costs. Variable costs consist of the costs for the materials, the labor, and the utilities. The fixed costs capture the equipment, tooling, building, maintenance, overhead, and capital. To estimate all these quantities, the number of labor hours and the cycle time (CT) required by the various manufacturing processes are carefully estimated. In addition, a virtual model of a blade manufacturing facility is created.

The model is applicable to blades made with a conventional structural-skin geometry, namely two straight spar caps, one or more shear webs, leading- and trailing-edge reinforcements, and an outer shell skin with a sandwich structure. Additionally, the model is valid for blades with mild sweep and prebend. As long as the blade curvature is not excessive, the manufacturing process is unchanged. Finally, the model assumes that spar caps, root inserts, and shear webs are preinfused and then inserted into the low- and high-pressure skin molds.

The model loses validity for blades characterized by a more complex internal geometry, such as blades with tapered and/or pultruded spar caps, segmented blades, blades made with manufacturing methods different than VARTM, and so on. Blades that deviate from the assumptions of the model require modifications (possibly minor) to the model.

The model was initially developed in a blade manufacturing facility to analyze the manufacturing process and identify inefficiencies in labor and cycle times. In a second step of development, the details of the models were fleshed out for cost and manufacturing process modeling. The model involves a large number of assumptions regarding the steps, the work rate for each steps, how workers and teams are formed, and so on. These assumptions originate from real blade factories and have been calibrated such that the overall cost and cycle times match available empirical industry data. Originally implemented in a large Excel file, the model has now been implemented in a Python code and coupled to the Wind-Plant Integrated System Design Engineering Model (WISDEM) framework. WISDEM is a multiyear, multidisciplinary design, analysis, and optimization (MDAO) framework developed at the National Renewable Energy Laboratory (NREL) (Dykes et al. 2014) and freely available in an online repository on github.com/WISDEM. MDAO models have been increasingly adopted within the design of wind turbines. These methods offer the opportunity to run design optimization studies in an automatic manner, generating a multitude of results in a relatively limited amount of time. In addition, properly defined automatic design procedures ensure that all synergies and constraints between disciplines are taken into account at the initial stages of multiple design iterations. This represents undeniable progress compared to former methods, where single discipline experts performed the detailed design of each wind turbine component and only at a second stage integrated all of them together, iterating when necessary. The single iteration design relies on the expertise of the single designers, in which the existing couplings between disciplines can only be captured partially. MDAO aims at providing a valuable alternative.

The blade cost model is fully coupled with RotorSE, the rotor design optimization model of WISDEM. This means that each blade cost execution can be called from RotorSE automatically. It is important to highlight that the Python code implementing this model consistently adopts the International System of Units. The Python code implementing the blade cost model works by reading in PreComp input files that describe the outer blade shape and internal structure. PreComp is the standard cross-sectional analysis tool within WISDEM. The PreComp input files are typically generated by Numad, a three-dimensional finite element method preprocessing code implemented in MATLAB and developed at Sandia National Laboratories (SNL).

This documents presents six sections. After this introduction, Section 2 presents the bill of materials estimation. This includes composite fabrics, composite resin and hardener, sandwich structure cores, coating material, adhesives, metallic parts, and finally a list of consumables. Section 3 discusses the detailed procedures to estimate the labor and the cycle time behind a VARTM process of a blade. These quantities are then used in Section 4 to build a virtual model of a factory and estimate the total blade costs. In Section 5, the model is run to compute the bill of materials, labor and cycle time, and the total costs of three blades, the 33.25 meter (m) blade developed in the WindPACT study (Malcolm and Hansen 2006), the blade of the IEA Wind Task 37 land-based reference wind turbine (Bortolotti et 
al. 2019), and finally the SNL-100-03 blade, which is the latest design of the 100-meter-long blade series developed at SNL (Griffith and Richards 2014). These blades have varying lengths between 30 and $100 \mathrm{~m}$, spanning the range of lengths currently present in the wind energy market. Finally, Section 6 concludes the document with an outlook on future work. 


\section{Bill of Materials}

The bill of materials of a blade lists the volume, mass, and cost of all materials used during manufacturing. The bill of materials in the model is split into composite materials, sandwich cores, coating, matrix and adhesive materials, metallic parts, such as root bolts and lightning protection system (LPS), and finally consumables. The next sections elaborate on the calculation of the volume, mass, and cost for each of these materials.

\subsection{Composite Fabrics, Sandwich Core, and Coating}

This section is the simplest, from a conceptual point of view, and the hardest, from an implementation point of view. The model simply estimates the volume of each material and multiplies it by the density and by the unit cost. The Python code achieves this by reconstructing the blade structure from the PreComp input files. These files describe a blade structure at a predefined number of spanwise stations with the following characteristics:

- Chord, twist, and pitch axis position

- Nondimensional airfoil shape

- Positions of a number of panels located chordwise.

For each panel along the chord, a ply stacking sequence is then defined by reporting:

- Chordwise coordinates of the panel

- Number of plies

- Thickness of each ply

- Material ID.

The Python code reads all PreComp input files and stores all quantities in various dictionaries, borrowing some of the routines and data structures from RotorSE.

For each material, values of unit cost and waste factor during manufacturing are provided. In addition, a flag specifying whether the material needs cutting or not is specified. Typically, only biaxial (Bx) and triaxial (Tx) composite fabrics need cutting (see Section 3.1). Finally, if the fabric needs to be cut, the mass in kilograms (kg) of a single roll needs to be specified (see Section 3.1). Default prices of the composite fabrics, either glass fiber (GF) or carbon fiber (CF), sandwich core, foam, balsa wood, leading-edge (LE) tape, and coating are listed in Table 1. The leading-edge tape is a reinforcement typically placed along the leading-edge of wind turbine blades to minimize the effects of leading-edge erosion and extend the lifetime of the rotor.

Table 1. Default Prices for Composite Fabrics, Sandwich Core, and Coating

\begin{tabular}{lclc}
\hline Material & Price & Material & Price \\
\hline Bx GF & $\$ 3.00 / \mathrm{kg}$ & Tx GF & $\$ 2.86 / \mathrm{kg}$ \\
UD GF & $\$ 1.87 / \mathrm{kg}$ & UD CF & $\$ 30.00 / \mathrm{kg}$ \\
LE tape & $\$ 2.00 / \mathrm{m}$ & Paint & $\$ 7.23 / \mathrm{kg}$ \\
Foam & $\$ 7.23 / \mathrm{kg}$ & Balsa & $\$ 13 / \mathrm{m}^{2}$ \\
\hline
\end{tabular}

Often PreComp files lump each material into an artificial single ply in a given location of the blade. The code then loops spanwise and chordwise across all panels and recomputes a realistic finite number of plies. When the thickness is not an exact multiple of the ply thickness, the code offers the possibility to round the number of plies.

For the sandwich fillers, either foam or balsa wood, a simplified approach is adopted where the unit price is given for a unit area. This simplification should be overcome in a next version of the model. 


\subsection{Matrix and Adhesive}

A conventional composite laminate is made of a fabric and a matrix. For the matrix, this model assumes the use of epoxy, which is, as most matrices, made of a combination of resin and hardener. Both resin and hardener are liquid, but when mixed in a given mass ratio, they initiate an exothermic chemical reaction that brings them to a solid state.

In the model, the quantities of both resin and hardener are computed first by estimating the matrix density and unit cost from a user-defined mix mass-ratio. Then, by multiplying the volume of each material by 1 minus the fiber volume fraction, the amount of matrix used in each portion of the blade is computed.

$$
\text { Volume matrix }=\text { Volume Laminate } *(1-\text { Fiber Volume Fraction })
$$

Additionally, the amount of adhesive needed to glue the various components together is computed. Adhesives are also typically made of a resin and a hardener (part A and B in the code). These are characterized by their own unit cost and density. Mass and volume mix ratios are set among the model inputs. Adhesive is modeled in the top and bottom edges of each shear web as well as along leading- and trailing-edge. The volume of the adhesive is obtained by multiplying the length of the bonding lines, which is reconstructed from the PreComp files, the width of the flanges, and an adhesive thickness. The code models different widths and thicknesses for leading- and trailing-edge (TE), and shear webs. Default values for width are 62.7 millimeters $(\mathrm{mm})$ for the edges and $75.4 \mathrm{~mm}$ for the shear webs. For the thickness, default values are $6 \mathrm{~mm}$ and $8 \mathrm{~mm}$, respectively.

In terms of prices, default values are reported in Table 2.

Table 2. Default Prices for Composite Matrix and Adhesive

\begin{tabular}{lclc}
\hline Material & Price & Material & Price \\
\hline Resin & $\$ 3.63 / \mathrm{kg}$ & Hardener & $\$ 3.63 / \mathrm{kg}$ \\
Adhesive Part A & $\$ 9.00 / \mathrm{kg}$ & Adhesive Part B & $\$ 9.00 / \mathrm{kg}$ \\
\hline
\end{tabular}

\subsection{Hub Connection and Lightning System}

Blades are mostly made of composite materials, but a few metallic parts are present. For a conventional blade, these are the root bolts connecting the blades to the hub and the lightning protection system, which runs from blade tip to blade root.

By default, the model assumes blade root T-bolts of $30 \mathrm{~mm}$ in diameter, whose number along the blade root is either user-defined or assumed proportional to the root circumference. In the latter case, bolts are assumed to be equally spaced every $0.15 \mathrm{~m}$. The default value for the unit cost of a T-bolt is $\$ 25$, whereas each barrel nut (the metallic part locking the T-bolt in place) is assumed to cost $\$ 12$. Notably, modern longer blades adopt female-threaded root inserts rather than T-bolts. This is a limitation to this model that will need to be addressed in future studies.

In addition, a lightning protection system is a necessity in almost every blade. This typically consists of a metal button, often named puck or interceptor, located at the blade tip and connected to the ground via a metallic cable. At midspan of the blade, two extra branches are also typically present connecting the leading- and trailing-edge.

This model assumes a unit cost and unit mass of the lightning protection system equal to $1 \mathrm{~kg} / \mathrm{m}$ and $\$ 40 / \mathrm{m}$, respectively. These value have been scaled based on the values of a 61.5-meter-long blade. The scaling factor is the sum of blade length and chord length at midspan. 


\subsection{Consumables}

A blade manufacturing process involves the use of several consumables. This section discusses this list and how to estimate the need for each consumable. For each consumable, costs with and without waste are estimated.

\section{Peel-Ply}

A peel-ply, also called release fabric, is a permeable, synthetic cloth that is draped over the fabric ready to be infused. Once the infusion as well as the curing processes are completed, the peel-ply is peeled off. Thanks to the peel-ply, the infused product features a perfectly smooth surface that is ready for a sanding step or the next round of infusion.

The amount of peel-ply is estimated by first summing up the areas of each shear web and the low and high pressure (LP-HP) skin molds and then by multiplying this area by a unit cost, expressed in $\$ / \mathrm{m}^{2}$. The areas include the flanges.

$$
\text { Total Cost }=(\text { Area Webs }+ \text { Area Molds }+ \text { Area Spar Caps }+ \text { Area Root }) * \text { Unit Cost }
$$

The typical inputs of the model are reported in Table 3.

Table 3. Standard Inputs for Computing the Cost of the Peel-Ply

\begin{tabular}{lc}
\hline Input & Value \\
\hline Cost per area & $\$ 1.94 / \mathrm{m}^{2}$ \\
Waste & $15 \%$ \\
\hline
\end{tabular}

\section{Nonsand Tape}

Nonsand tape is used on the bonding surfaces of the main skins, namely where the shear webs are inserted and along leading- and trailing-edge. This helps reducing the labor associated with having to sand and prepare the bonding surfaces. It is applied directly next to the laminate stack and left on until moments before the bonding process. The cost of nonsand tape is estimated as proportional to the length of leading- and trailing-edge as well as webs length.

Total Cost $=$ Roll Width $* 2 *($ TE $/$ LE Length + Webs Length $) *$ Unit Cost

Table 4. Standard Inputs for Computing the Cost of the Nonsand Tape

\begin{tabular}{lc}
\hline Input & Value \\
\hline Cost per area & $\$ 1.67 / \mathrm{m}^{2}$ \\
Roll width & $0.127 \mathrm{~m}$ \\
Waste & $10 \%$ \\
\hline
\end{tabular}




\section{Chopped Strand}

Chopped strand material is a nonwoven fabric with short strands of fibers held together with a resin binder. It is commonly used to add bulk to a laminate stack or to promote a smooth surface finish. The cost of chopped strand is estimated as proportional to blade length.

$$
\text { Total Cost }=\text { Blade Length } * \text { Mass per Unit Length } * \text { Unit Cost }
$$

Table 5. Standard Inputs for Computing the Cost of the Chopped Strand

\begin{tabular}{lc}
\hline Input & Value \\
\hline Cost per mass & $\$ 2.16 / \mathrm{kg}$ \\
Mass per length & $0.037 \mathrm{~kg} / \mathrm{m}$ \\
Waste & $5 \%$ \\
\hline
\end{tabular}

\section{Tackifier Adhesive}

Tackifier adhesive is used in small amounts to adhere layers of fiberglass or consumables during the layup process, so that they do not move relative to each other. Tackifier adhesive comes in bulk and cans. The cost of both components is estimated proportional to the mold areas, which are the sum of the areas of the molds of webs, spar caps, root preforms, and main shells. The areas include the flanges. The data used in the equations are reported in Table 6.

$$
\text { Total Cost Bulk = Volume Bulk per Area } *(\text { Area Molds }) * \text { Unit Cost }
$$

Total Cost Cans $=$ Can per Area $*($ Area Molds $) *$ Unit Cost

Table 6. Standard Inputs for Computing the Cost of the Tackifier Adhesive

\begin{tabular}{llc}
\hline Component & Input & Value \\
\hline \multirow{4}{*}{ Bulk } & Cost per volume bulk & $\$ 6,762.8 / \mathrm{m}^{3}$ \\
& Volume per area & $3.06 \mathrm{e}-5 \mathrm{~m}^{3} / \mathrm{m}^{2}$ \\
& Waste & $5 \%$ \\
\hline \multirow{3}{*}{ Cans } & Cost per can & $\$ 6.65 / \#$ \\
& Cans per area & $0.022 \# / \mathrm{m}^{2}$ \\
& Waste & $5 \%$ \\
\hline
\end{tabular}

\section{Release Agent}

Release agent is applied to the mold prior to layup the composites so that the parts are easily released and do not stick to the surface of the mold. The type of release agent is selected based on the resin being used. The cost of the release agent is estimated as proportional to the mold areas, including the flanges. 
Total Cost $=$ Volume per Area $*($ Area Webs + Area Molds + Area Spar Caps + Area Root $) *$ Unit Cost

Table 7. Standard Inputs for Computing the Cost of the Release Agent

\begin{tabular}{lc}
\hline Input & Value \\
\hline Cost per volume & $\$ 15,691.82 / \mathrm{m}^{3}$ \\
Volume per area & $2.57 \mathrm{e}-5 \mathrm{~m}^{3} / \mathrm{m}^{2}$ \\
Waste & $5 \%$ \\
\hline
\end{tabular}

\section{Flow Medium}

A flow medium is used during the infusion process to aid in resin flow from the resin inlet to the laminate stack. The cost of the flow medium is estimated as proportional to mold areas, including the flanges.

$$
\text { Total Cost }=\text { Coverage } *(\text { Area Webs }+ \text { Area Molds }+ \text { Area Spar Caps }+ \text { Area Root }) * \text { Unit Cost }
$$

Table 8. Standard Inputs for Computing the Cost of the Flow Medium

\begin{tabular}{lc}
\hline Input & Value \\
\hline Cost per area & $\$ 0.646 / \mathrm{m}^{2}$ \\
Coverage & $70 \%$ \\
Waste & $15 \%$ \\
\hline
\end{tabular}

\section{Tubing}

Manufacturing techniques and materials evolve continuously. This model assumes the use of tubes for both vacuum and resin feed lines. The tubes come in various diameters, which are selected based on the required flow rates and other parameters. The cost of tubing is estimated as proportional to blade length.

$$
\text { Total Cost }=\text { Length per Blade Length } * \text { Blade Length } * \text { Unit Cost }
$$

Recently, processes started including other solutions to basic tubes, such as omega channels and spiral tubing. These will be included in future versions of the cost model.

\section{Tacky Tape}

Tacky Tape is similar to a double-sided tape and it is applied before the vacuum bag along the edges of each mold. Once Tacky Tape is applied, its outer paper layer is peeled off and the vacuum bag can be applied and sealed along the edges. The cost of Tacky Tape is assumed proportional to 10 times the blade length. 
Table 9. Standard Inputs for Computing the Cost of the Tubing

\begin{tabular}{lc}
\hline Input & Value \\
\hline Diameter & $3 / 8$ inches (in) \\
Cost per length & $\$ 0.23 / \mathrm{m}$ \\
Length per length blade & $5 \mathrm{~m} / \mathrm{m}$ \\
Waste & $10 \%$ \\
\hline Diameter & $1 / 2 \mathrm{in}$ \\
Cost per length & $\$ 0.23 / \mathrm{m}$ \\
Length per length blade & $5 \mathrm{~m} / \mathrm{m}$ \\
Waste & $10 \%$ \\
\hline Diameter & $5 / 8$ in \\
Cost per length & $\$ 0.49 / \mathrm{m}$ \\
Length per length blade & $5 \mathrm{~m} / \mathrm{m}$ \\
Waste & $10 \%$ \\
\hline Diameter & $3 / 4 \mathrm{in}$ \\
Cost per length & $\$ 0.62 / \mathrm{m}$ \\
Length per length blade & $5 \mathrm{~m} / \mathrm{m}$ \\
Waste & $10 \%$ \\
\hline Diameter & $7 / 8 \mathrm{in}$ \\
Cost per length & $\$ 0.49 / \mathrm{m}$ \\
Length per length blade & $5 \mathrm{~m} / \mathrm{m}$ \\
Waste & $10 \%$ \\
\hline & \\
& \\
Total Cost $=\left(\frac{10 * \text { Blade Length }}{\text { Roll Length }}\right) *$ Roll Cost \\
& \\
&
\end{tabular}

Table 10. Standard Inputs for Computing the Cost of Tacky Tape

\begin{tabular}{lc}
\hline Input & Value \\
\hline Roll length & $3.5 \mathrm{~m}$ \\
Cost per roll & $\$ 21.11 /$ roll \\
Waste & $5 \%$ \\
\hline
\end{tabular}

\section{Masking Tape}

Masking tape is used to section off the area of the mold where Tacky Tape will be applied to for vacuum bagging. This is to protect the surface during mold release application so that the area of the mold that needs to have the tape applied does not become too slippery for Tacky Tape to adhere to. The cost of masking tape is estimated as proportional to blade length.

$$
\text { Total Cost }=\text { Blade Length } * \text { Roll per Length } * \text { Roll Cost }
$$


Table 11. Standard Inputs for Computing the Cost of the Masking Tape

\begin{tabular}{llc}
\hline Tape & Input & Value \\
\hline \multirow{4}{*}{ Tape } & Roll length & $0.328 \mathrm{~m}$ \\
& Cost per roll & $\$ 5.50 /$ roll \\
& Waste & $10 \%$ \\
\hline
\end{tabular}

\section{Chop Fibers}

Chop fibers are used to fill small gaps between the structural components as a reinforcement. At the time of infusion, this prevents the creation of large volumes of pure resin, which could be prone to cracks. The cost of chop fibers is assumed as proportional to the blade outer area.

$$
\text { Total Cost }=\text { Mass per Area } * \text { Blade Outer Area } * \text { Unit Cost }
$$

Table 12. Standard Inputs for Computing the Cost of the Chop Fiber

\begin{tabular}{lc}
\hline Input & Value \\
\hline Cost per mass & $\$ 6.19 / \mathrm{kg}$ \\
Mass per area & $9.76 \mathrm{e}-3 \mathrm{~kg} / \mathrm{m}^{2}$ \\
Waste & $10 \%$ \\
\hline
\end{tabular}

White Lightning

White lightning is a finishing filler used to close small cracks and gaps. Its cost is assumed proportional to the blade outer area.

$$
\text { Total Cost }=\text { Volume per Area } * \text { Blade Outer Area } * \text { Unit Cost }
$$

Table 13. Standard Inputs for Computing the Cost of White Lightning Protection

\begin{tabular}{lc}
\hline Input & Value \\
\hline Cost per volume & $\$ 3,006.28 / \mathrm{m}^{3}$ \\
Volume per area & $2.04 \mathrm{e}-5 \mathrm{~m}^{3} / \mathrm{m}^{2}$ \\
Waste & $10 \%$ \\
\hline
\end{tabular}

\section{Hardener}

Extra hardener is always needed in a blade manufacturing process. This is mixed with extra resin to chemically react and initiate the curing process for side activities. The cost of the hardener is estimated as:

$$
\text { Total Cost }=\text { Tubes per Area } * \text { Blade Outer Area } * \text { Unit Cost }
$$


Table 14. Standard Inputs for Computing the Cost of the Hardener

\begin{tabular}{lc}
\hline Input & Value \\
\hline Cost per tube & $\$ 1.65 /$ tube \\
Tubes per area & $0.012 \# / \mathrm{m}^{2}$ \\
Waste & $10 \%$ \\
\hline
\end{tabular}

\section{Putty}

Before the painting process, putty is often used to even out the blade outer surface. Its cost is assumed proportional to the blade outer area.

Total Cost $=$ Mass per Area $*$ Blade Outer Area $*$ Unit Cost

Table 15. Standard Inputs for Computing the Cost of the Putty

\begin{tabular}{lc}
\hline Input & Value \\
\hline Cost per mass & $\$ 6.00 / \mathrm{kg}$ \\
Mass per area & $0.0244 \mathrm{~kg} / \mathrm{m}^{2}$ \\
Waste & $10 \%$ \\
\hline
\end{tabular}

\section{Putty Catalyst}

The putty requires a catalyst, which is mixed to promote curing.

Total Cost $=$ Mass per Area $*$ Blade Outer Area $*$ Unit Cost

Table 16. Standard Inputs for Computing the Cost of the Putty Catalyst

\begin{tabular}{lc}
\hline Input & Value \\
\hline Cost per mass & $\$ 7.89 / \mathrm{kg}$ \\
Mass per area & $4.88 \mathrm{e}-3 \mathrm{~kg} / \mathrm{m}^{2}$ \\
Waste & $10 \%$ \\
\hline
\end{tabular}




\section{Labor and Cycle Times}

This section presents a procedure to estimate the labor and the cycle time necessary to manufacture a multimegawatt wind turbine blade. The manufacturing process is split into 15 different operations. These are:

1. Material cutting

2. Infusion of the components

3. Assembly

4. Demold

5. Trim

6. Overlay

7. Postcure

8. Root cut and drill

9. Root fasteners installation

10. Surface preparation

11. Paint

12. Surface finishing

13. Weight and balance

14. Inspection

15. Shipping preparation.

Out of these operations, some have more crucial time constraints than others. These are the ones associated with the main mold, namely the assembling of all preinfused components, the main infusion of the two half-molds and the demolding. The cycle time of these three operations together is typically referred to as "gating." Blade factories usually try to have the gating cycle time equal to 24 hours (hr) to schedule a repetitive routine throughout the week as well as to minimize the number of main molds.

This model assumes that the number of workers involved in the gating operations is set to achieve a gating cycle time of 24 hours. To start, the cycle time for demolding is computed. This is assumed independent of the number of workers; see Section 3.4. Then, the size of the team busy with the infusion of the LP and HP skins is set to respect a cycle time that is set equal to $70 \%$ of the difference between 24 hours and the demolding cycle time:

$$
C T_{L P-H P \text { skins }}=0.7 *\left(24 \mathrm{hr}-C T_{\text {demold }}\right)
$$

Finally, the remaining time in the 24-hour cycle is used to assemble the two half-molds, see Section 3.3:

$$
C T_{\text {assembly }}=0.3 *\left(24 \mathrm{hr}-C T_{\text {demold }}\right)
$$

In contrast, the number of workers busy with all of the other operations is fixed and set as a user input. The following sections briefly explain all of the 15 processes and present the formulas assumed to estimate the number of labor hours as well as the cycle time. 


\subsection{Material Cutting}

The manufacturing process of a blade manufactured via VARTM typically starts by cutting the layers of fabric needed in the mold. These are cut from rolls of fabric that are purchased from material suppliers. Fabrics are cut to specific shapes before being placed in a mold. Computer-controlled cutting tables are used to do the cutting. Once cut, sets of fabric patterns for a given portion of the blade are assembled into kits to ease fabric placement in the mold. Overall, four operations are distinguished:

- Loading of the rolls and preparation of the cutting machines

- Material cutting

- Kitting

- Cleanup

This set of four operations has to be performed for all composite fabrics except unidirectional layers, which are assumed to have constant roll width and are usually cut at the mold or not cut at all. This model assumes that each cutting station is operated by a team of two workers. In case of excessive cycle time, the number of stations is then increased; see Section 4. The computation of the labor hours and cycle times needed for each operation is described in detail next.

\section{Loading of the Fabric Rolls and Machine Preparation}

For this operation, each roll of fabric is estimated to be loaded by the two workers in 15 minutes time. The amount of rolls to be loaded is the sum for all materials of the roundup of the ratio of the mass of each material, including waste factors, and a typical roll mass:

$$
\begin{gathered}
\text { Number of Rolls }=\left\lceil\frac{\text { Mass } *(1+\text { Waste Factor })}{\text { Roll Mass }}\right\rceil \\
\text { Labor }=\text { Number of Rolls } * 0.25 \mathrm{hr} * 2 \text { Workers } \\
C T=\text { Number of Rolls } * 0.25 \mathrm{hr}
\end{gathered}
$$

\section{Material Cutting}

The amount of labor hours needed to cut each fabric is estimated as the ratio of the total ply area (including wastes) to the machine cutting rate. The ply areas for each fabric are estimated by postprocessing the data included in the PreComp files. The ratio is then multiplied by the number of personnel. For the actual cutting, a standard cutting rate for modern machines is $696.5 \mathrm{~m}^{2} / \mathrm{hr}\left(833 \mathrm{yd}^{2} / \mathrm{hr}\right)$. Unidirectional layers are usually not cut. The cycle time is equal to the number of labor hours divided by the number of workers involved in the operation.

$$
\begin{gathered}
\text { Labor }=\frac{\text { Ply Area }}{\text { Machine Rate }} * 2 \text { Workers } \\
C T=\frac{\text { Labor }}{2 \text { Workers }}
\end{gathered}
$$




\section{Kitting}

Kitting is the operation of assembling different portions of fabric together following the right stacking sequence. This process simplifies the layup processes taking place at the mold. The amount of labor hours needed for kitting is assumed as the cycle time of the cutting process multiplied by 2 , which is the number of workers involved in the operation. The cycle time for kitting is instead assumed at 0 hours, as the two workers kit while the cutting machine runs, so the cycle time is captured in the cutting (machine run) cycle time.

$$
\begin{gathered}
\text { Labor }=C T_{\text {cutting }} * 2 \text { Workers } \\
C T=0
\end{gathered}
$$

\section{Cleanup}

After cutting and kitting the fabrics, it is common to have layup and waste fabrics in the working area. Thus, before moving on, a cleanup step is necessary. It is assumed that approximately 1 square yard of material can be cleaned up every 5 seconds by 1 worker. This results in a cleanup rate of $602 \mathrm{~m}^{2} / \mathrm{hr}$ per person. The labor hours and the cycle time are then estimated as the ratio of waste area to cleanup rate:

$$
\begin{aligned}
\text { Labor } & =\frac{\text { Waste Area }}{\text { Cleanup Rate }} \\
C T & =\frac{\text { Labor }}{2 \text { Workers }}
\end{aligned}
$$

\subsection{Infusion of Components}

Once the fabrics have been cut to the right size, the actual infusion process can begin. During a VARTM infusion process of a modern wind turbine blade, several infusions are performed, producing various components that are later assembled together. These components are the LP and HP sides of the root inserts, the one or more shear webs, the two or more spar caps, and finally the LP and HP skins. The infusion process is made of 14 steps:

- Preparation of the tools

- Layup of the composite fabrics

- Application of the peel-ply

- Application of the flow medium

- Application of the feed lines

- Application of the vacuum lines

- Application of Tacky Tape

- Application of the vacuum bag

- Pull of full vacuum

- Check of vacuum leaks

- Actual infusion 
- Curing process

- Operations of debagging

- Operations of demolding.

Six additional steps are then needed for some of the components:

- Placement of the sandwich core (usually in the shear webs and in portions of the LP and HP skins)

- Insertion of the preformed root inserts into the mold (only for LP and HP skins)

- Insertion of the spar caps into the mold (only for LP and HP skins)

- Insertion of additional layers in the root region (only for LP and HP skins)

- Insertion of additional layers in the trailing-edge region (only for LP and HP skins)

- Insertion of additional inner layers into the whole mold (only for LP and HP skins).

As presented earlier, the assumption of the model is that the infusion of the nongating components, namely root preforms, spar caps, and shear webs, assumes a fixed size of the crews of workers, whereas the infusion of LP and HP skins adopts the frozen cycle time of Equation 3.1. For the root preforms, teams of two are assumed. For the shear webs and the spar caps, teams are composed of 10 workers.

The following sections present all 20 manufacturing steps and discuss the various assumptions adopted to estimate the labor hours and the cycle time.

\section{Preparation of the Tools}

The infusion process starts by preparing all necessary tools. Here, labor is estimated with an underlying assumption that one person can prepare $0.2 \mathrm{~m}^{2}$ in 1 minute, that makes $12 \mathrm{~m}^{2} / \mathrm{hr}$. In addition, the model assumes that the mold can be prepared once every five infusions, here referred to as pulls. Before the sixth infusion, the model assumes that the mold needs to be cleaned and release coated.

Labor and cycle times are then expressed as:

$$
\begin{gathered}
\text { Labor }=\frac{\text { Tool Area }}{12 m^{2} / h r * 5 \text { Pulls }} \\
C T=\frac{\text { Labor }}{\# \text { Workers }}
\end{gathered}
$$

\section{Insert the Preformed Root in the Mold}

When preparing the molds of the LP and HP skins, each premanufactured root preform has to be inserted in each mold. This process is performed by $25 \%$ of the workers of the team and it is assumed to take 15 minutes.

$$
\begin{gathered}
\text { Labor }=0.25 \mathrm{hr} * 0.25 * \# \text { Workers } \\
C T=0.25 \mathrm{hr}
\end{gathered}
$$


Table 17. Layup Rates and Number of Workers for the Fabric Layup

\begin{tabular}{lc}
\hline Component & Layup rate \\
\hline Root preform & $8 \mathrm{ply} / \mathrm{hr} /$ worker \\
Shear webs & $24 \mathrm{~m}^{2} / \mathrm{hr} /$ worker \\
LP-HP skins & $30 \mathrm{~m}^{2} / \mathrm{hr} /$ worker \\
Spar caps & $110 \mathrm{~m} / \mathrm{hr} /$ worker \\
\hline
\end{tabular}

\section{Layup of the Composite Fabrics}

This step consists of laying the composite fabric in the mold. The amount of fabric as well as the laying rate greatly depend on the components, on its geometry, and on its fabric. For a relatively small and complex component such as the root preform, the underlying assumption is that each worker can lay down composite layers at a rate of $8 \mathrm{plies} / \mathrm{hr}$. In longer components characterized by smaller variations in thickness, such as the shear webs, a realistic assumption is that each worker can lay down layers at a rate of $24 \mathrm{~m}^{2} / \mathrm{hr}$. Finally, for the LP and HP skins, the layers can be laid at an approximate rate of $30 \mathrm{~m}^{2} / \mathrm{hr} /$ worker.

The laying of the rolls of unidirectional fabric for the spar caps and the reinforcement of the edges can be performed faster. A realistic assumption for the spar caps is that each worker can lay down, by rolling out, 55 meters of fabric length in approximately 30 minutes. This includes the laying of the adhesive. This sums up to a rate of $110 \mathrm{~m} / \mathrm{hr} /$ worker. In the spar caps, the sides and the flanges of a spar cap mold should be assumed to equal about 1.5 times the area of the spar cap itself. This assumption is made for tool preparation purposes.

Overall, the labor hours and the cycle time for the layup of the composite fabrics can be formulated as:

$$
\begin{aligned}
\text { Labor } & =\frac{\text { Ply Area }}{\text { Layup Rate }} \\
C T & =\frac{\text { Labor }}{\# \text { Workers }}
\end{aligned}
$$

Table 17 lists the layup rates assumed for the fabric layup in each component.

\section{Insert the Spar Caps into the Mold}

Similar to the root preform, the preinfused spar caps (SC) need to be inserted into the LP and HP skin molds. The task is performed by $25 \%$ of the team, assuming that the workers can insert a 30-meter-long (or less) spar cap in 15 minutes, with an additional premium of 5 minutes per extra $10 \mathrm{~m}$ of spar cap length above 30 meters $(0.5$ minute per meter).

$$
\begin{gathered}
\text { Labor }= \begin{cases}0.25 \mathrm{hr} * 0.25 * \# \text { Workers }, & \text { if SC Length } \leq 30 \mathrm{~m} \\
\left(0.25 \mathrm{hr}+(S C \text { Length }-30 \mathrm{~m}) * \frac{0.5}{60} \mathrm{~m} / \mathrm{hr}\right) * 0.25 * \# \text { Workers, } & \text { else }\end{cases} \\
C T=\frac{\text { Labor }}{0.25 * \# \text { Workers }}
\end{gathered}
$$




\section{Insert Additional Layers in the Root Region}

In both LP and HP, additional layers of fabric are usually inserted in the root region. This model assumes that this activity is performed at a rate of $16 \mathrm{plies} / \mathrm{hr} /$ worker and that $25 \%$ of the team is busy with this task.

$$
\begin{aligned}
\text { Labor } & =\frac{\# \text { Extra Root Plies }}{16 \# / \text { hr } / \text { worker }} \\
C T & =\frac{\text { Labor }}{0.25 * \# \text { Workers }}
\end{aligned}
$$

\section{Placement of the Sandwich Core}

In a typical blade, shear webs and both the forward and aft panels of LP and HP skins have a sandwich structure, which means that in between two layers of composite, a lightweight structural filler is inserted to increase resistance to buckling. A single worker can lay down approximately $12 \mathrm{~m}^{2}$ in 1 hour; $75 \%$ of the team performs this activity.

$$
\begin{aligned}
& \text { Labor }=\frac{\text { Area with Core }}{12 \mathrm{~m}^{2} / \mathrm{hr}} \\
& C T=\frac{\text { Labor }}{0.75 * \text { \# Workers }}
\end{aligned}
$$

\section{Insert Reinforcements in the Edges}

In addition to the process described in Equations 3.16 and 3.17, additional layers of unidirectional fabric are rolled out in the leading- and trailing-edge region during the preparation of the infusion for the LP and HP skins. The assumption is that each worker can lay down unidirectional reinforcement at a rate of $96 \mathrm{~m} / \mathrm{hr} /$ worker. The whole team performs this task.

$$
\begin{gathered}
\text { Labor }=\frac{\text { LE } / \text { TE Ply Length }}{96 \mathrm{~m} / \mathrm{hr}} \\
C T=\frac{\text { Labor }}{\# \text { Workers }}
\end{gathered}
$$

For some blade designs, these leading- and trailing-edge unidirectional reinforcements are laid up and cured in a separate mold and inserted during the skin layup process. This possibility is currently not supported by this model, but it could be added by treating the reinforcements as thin spar caps.

\section{Insert Additional Inner Layers in the Whole Mold}

After all the processes described previously, additional skin layers need to be inserted into the molds of the LP and HP skins. Here, the procedure follows the one described in Equations 3.16 and 3.17 (i.e., blades longer than 30 meters require a crew of multiple workers each working at a rate of $30 \mathrm{~m}^{2} / \mathrm{hr} /$ worker). The whole team is busy with this task.

$$
\text { Labor }=\frac{\text { Total Ply Area }}{30 m^{2} / h r}
$$




$$
C T=\frac{\text { Labor }}{\# \text { Workers }}
$$

\section{Preparation of the Infusion}

Once all the preliminary steps described earlier are completed, several steps to prepare for the actual infusion are performed. These are:

- Application of the nonsand tape and of the peel-ply

- Application of the flow medium

- Application of the feed lines

- Application of the vacuum lines

- Application of Tacky Tape

- Application of the vacuum bag

- Pull of full vacuum

- Check of vacuum leaks.

All crew members work in parallel on all tasks.

\section{Application of the Nonsand Tape and of the Peel-Ply}

This model assumes that each worker can lay down $20 \mathrm{~m}^{2}$ of nonsand tape and peel-ply per hour, including the adhesive.

$$
\begin{gathered}
\text { Labor }=\frac{\text { Infusion Area }}{20 \mathrm{~m}^{2} / \text { hr } / \text { worker }} \\
C T=\frac{\text { Labor }}{\# \text { Workers }}
\end{gathered}
$$

\section{Application of the Flow Medium}

The flow medium consists of a mesh applied in the mold on top of the peel-ply to facilitate the flow of resin and prevent dry spots during the infusion. Similarly to the application of the peel-ply described earlier, this model assumes that each worker can lay down at a rate of $10 \mathrm{~m}^{2} / \mathrm{hr}$.

$$
\begin{gathered}
\text { Labor }=\frac{\text { Infusion Area }}{10 \mathrm{~m}^{2} / \mathrm{hr} / \text { worker }} \\
C T=\frac{\text { Labor }}{\# \text { Workers }}
\end{gathered}
$$




\section{Application of the Feed Lines}

The infusion of each component requires a specific setup and a different overall length of the lines is assumed.

For the root preform, one feed line is assumed to be placed down the center of each preform and be equal in length to the root span. Radial feed lines placed every $500 \mathrm{~mm}$ (along the full $1 / 2$ circumference) complete the setup. The code always rounds up the number of feed lines.

$$
\text { Feed Line Length }=\text { Root } L+\text { Half Root Circ. } *\left\lceil\frac{\text { Root } L}{500 ~ m m}\right\rceil
$$

For the LP and HP skins, one line feeding the center of the root span is assumed, together with two radial feed lines per meter of root span for the whole half circumference. In addition, one feed line runs along the whole blade center from the tip, stopping two meters before the root, and finally four additional feed lines run for an average length of $65 \%$ of the blade span parallel to the center feed line.

$$
\text { Feed Line Length }=\text { Root } L+\text { Half Root Circ. } *\left\lceil\frac{\text { Root } L}{500 ~ m m}\right\rceil+\text { Blade } L-2+4 * 0.65 * \text { Blade L }
$$

For the shear webs, a single feed line running along the whole length of the web is assumed.

$$
\text { Feed Line Length }=\text { Web Length }
$$

Finally, in each spar cap a feed line runs along the whole length on one side.

$$
\text { Feed Line Length }=\text { Spar Cap Length }
$$

The labor to install the feed lines can be estimated as the feed line length divided by a lay rate equal to $7.5 \mathrm{~m} / \mathrm{hr} / \mathrm{worker}$ for root preform, spar caps, and shear webs and $10 \mathrm{~m} / \mathrm{hr} /$ worker for LP and HP skins.

$$
\begin{gathered}
\text { Labor }=\frac{\text { Feed Line Length }}{\text { Lay Rate }} \\
C T=\frac{\text { Labor }}{\# \text { Workers }}
\end{gathered}
$$

Please note that this model accounts for the labor to fabricate feed lines (mesh and springs) and vacuum lines (rope and breather cloth).

\section{Application of the Vacuum Lines}

The application of the vacuum lines follows a similar but simpler pattern. For the root preforms, one vacuum line is assumed per side along the span length of the preforms, so a total of two times the root preforms length.

$$
\text { Vacuum Line Length }=2 * \text { Root Length }
$$


For the LP and HP skins, a single vacuum line around the entire perimeter of the blade (except at the root) is assumed.

$$
\text { Vacuum Line Length }=\text { Mold Perimeter }
$$

For the shear webs and the spar caps, one vacuum line per side along the span length can be assumed.

$$
\text { Vacuum Line Length }=2 * \text { Span Length }
$$

From the vacuum line length it is possible to estimate labor and cycle time. The assumed rate is $20 \mathrm{~m} / \mathrm{hr} /$ worker. For all components, half of the team applies the vacuum lines, whereas the other half applies Tacky Tape (see the next section).

$$
\begin{aligned}
\text { Labor } & =\frac{\text { Vacuum Line Length }}{20 \mathrm{~m} / \mathrm{hr} / \text { worker }} \\
C T & =\frac{\text { Labor }}{0.5 * \# \text { Workers }}
\end{aligned}
$$

\section{Application of Tacky Tape}

In each component, Tacky Tape is applied along the outer perimeter. In terms of lay rate, for spar caps, shear webs, and root preforms the assumption is that one skilled worker can lay down $90 \mathrm{~m} / \mathrm{hr}$.

For the LP and HP skins, the process of applying Tacky Tape is instead somewhat faster and the model assumes then that one worker can lay down $1 \mathrm{~m}$ of Tacky Tape in 10 seconds for a hourly total of 360 meter. Half of the team performs this task.

$$
\begin{aligned}
\text { Labor } & =\frac{\text { Tacky Tape Length }}{\text { Application Rate }} \\
C T & =\frac{\text { Labor }}{0.5 * \# \text { Workers }}
\end{aligned}
$$

\section{Application of the Vacuum Bag}

The labor and the cycle time needed to apply the vacuum bag can be assumed proportional to the component area, including existing flanges. The assumed rate is here $7.5 \mathrm{~m}^{2} / \mathrm{hr} /$ worker and the whole team performs this activity.

$$
\begin{aligned}
\text { Labor } & =\frac{\text { Infusion Area }}{7.5 \mathrm{~m}^{2} / \text { hr } / \text { worker }} \\
C T & =\frac{\text { Labor }}{0.5 * \# \text { Workers }}
\end{aligned}
$$




\section{Pull of Full Vacuum}

The computation of labor and the cycle time needed to pull full vacuum follows the same assumptions taken for the application of the vacuum bag. Here, an approximate rate of $45 \mathrm{~m}^{2} / \mathrm{hr} /$ worker is assumed for all components, except for the main molds where a rate of $360 \mathrm{~m}^{2} / \mathrm{hr} /$ worker is assumed. The formulas for labor and cycle time become:

$$
\begin{aligned}
\text { Labor } & =\frac{\text { Infusion Area }}{\text { Rate }} \\
C T & =\frac{\text { Labor }}{\# \text { Workers }}
\end{aligned}
$$

\section{Check of Vacuum Leaks}

Once full vacuum is pulled, workers need to check and repair vacuum leaks. Each worker is assumed to be able to check vacuum at a rate of $180 \mathrm{~m} / \mathrm{hr} /$ worker for the main molds and $30 \mathrm{~m} / \mathrm{hr} /$ worker otherwise.

$$
\begin{gathered}
\text { Labor }=\frac{\text { Tacky Tape Length }}{\text { Rate }} \\
C T=\frac{\text { Labor }}{\# \text { Workers }}
\end{gathered}
$$

\section{Actual Infusion}

Once all the steps are completed, the actual infusion can start. A detailed infusion model would be needed to simulate the process and estimate the exact cycle time of the problem. To simplify things, an empirical regression formula is adopted, fitting data from four industrial manufacturers relating blade length to infusion time. A polynomial of up to order three is assumed. Table 18 lists the polynomial coefficients, together with the number of workers assumed for each component, namely a single one for the small components and three for LP and HP skins. Notably, the number of workers is independent on the blade characteristics.

Table 18. Coefficients of the Regression Polynomials to Estimate the Infusion Cycle Time, Measured in Minutes

\begin{tabular}{lccccc}
\hline & \# workers & $\mathrm{p} 0$ & $\mathrm{p} 1$ & $\mathrm{p} 2$ & $\mathrm{p} 3$ \\
\hline Root preform & 1 & 15 & 1 & 0 & 0 \\
Shear web & 1 & 11.983 & 0.3784 & 0 & 0 \\
Spar cap & 1 & 23.992 & 0.0037 & 0.0089 & 0 \\
Skin & 3 & 15.972 & 3.1484 & -0.0568 & 0.0004 \\
\hline
\end{tabular}

$$
\begin{gathered}
C T=\left(p 0+p 1 * \text { Blade Length }+p 2 * \text { Blade Lengt }^{2}+p 3 * \text { Blade Lengt }^{3}\right) / 60 \\
\text { Labor }=C T * \# \text { Workers }
\end{gathered}
$$

In the future, a more physical model to estimate the cycle time of the infusion should be developed. This should include a dependency of the cycle time to the blade chord. 


\section{Curing Process}

Once infusion is completed, the molds are heated up to cure the composite structure. The model assumes that for single parts such as spar caps, shear webs, and root preforms the necessary curing time equals a fixed time of 2 hours. This estimate is based on the dwell time, and during the curing, only one worker is required to supervise the process, while more workers would increase labor without generating benefits to the cycle time.

$$
\begin{gathered}
\text { Labor }=2 \mathrm{hr} \\
C T=2 \mathrm{hr}
\end{gathered}
$$

For thicker parts such as LP and HP skins, 3 hours of curing time per part are often necessary and the process is again supervised by a single worker.

$$
\begin{gathered}
\text { Labor }=3 \mathrm{hr} \\
C T=3 \mathrm{hr}
\end{gathered}
$$

In very large blades, structural components get thicker and this has a large impact to the curing cycle time. The curing time of the spar caps is especially critical, where maximum temperature ramp rates need to be carefully controlled to avoid excessive exothermic reactions. In a future release, this blade cost model should include a more accurate estimate of the curing cycle time.

\section{Debagging Operations}

After curing, the vacuum bags and other consumables are removed from the parts. Here, labor and cycle time are assumed to be proportional to the area of infusion, including the areas of the flanges. The rate of debagging depends on the geometrical complexity and on the size of the part, here an average value of $20 \mathrm{~m}^{2} / \mathrm{hr} /$ worker is assumed. The debagging operations are conducted by the whole team.

$$
\begin{aligned}
\text { Labor } & =\frac{\text { Infusion Area }}{20 m^{2}} \\
C T & =\frac{\text { Labor }}{\# \text { Workers }}
\end{aligned}
$$

\section{Demolding Operations for Precured Parts}

Demolding is the process of removing the infused root preforms, shear webs, and spar caps from the mold to prepare the final assembly. The demolding activity involves drilling lift holes, rigging, and operating the crane. The activity is conducted by the whole team and typically lasts 0.5 hours per component.

$$
\begin{gathered}
\text { Labor }=0.5 \mathrm{hr} * \# \text { Workers } \\
C T=0.5 \mathrm{hr}
\end{gathered}
$$




\section{Assembly Preparation and Trimming of Fiber Excess}

Similar to demolding, spar caps, shear webs, and root preforms go through a preparatory step to trim fiber excess and make the parts ready to be inserted or assembled in the LP and HP skin molds. For spar caps and shear webs, it is assumed that each worker can prepare and trim the spar caps at a rate of $1 \mathrm{~m}$ of component length per 2 minutes, which converts to $30 \mathrm{~m} / \mathrm{hr}$. For the root preforms, the rate is lowered to $6 \mathrm{~m} / \mathrm{hr} /$ worker.

$$
\begin{gathered}
\text { Labor }=\frac{\text { Component Length }}{\text { Rate }} \\
C T=\frac{\text { Labor }}{\# \text { Workers }}
\end{gathered}
$$

\subsection{Assembly}

As soon as all components, namely the LP and HP skins (that include spar caps and root preforms), and the shear webs have gone through the infusions steps described in Section 3.2, the assembling starts. This consists of 15 substeps:

- Insert shear webs into fixture

- Dry fit-boundary mark

- Remove nonsand tape

- Dispense lower adhesive

- Bond shear webs-lower

- Fillet shear web bonds

- Cure-lower

- Remove fixture

- Dry fit-upper

- Shear web height rework

- Dispense upper shear web and skin perimeter adhesive

- Close mold

- Install shear clips

- Cure-entire

- Open mold.

These steps are assumed to be performed by a bonding team similar in size to the layup/infusion team of the LP and HP skins. Given this crew of workers, the procedure to estimate the necessary labor and cycle time is elaborated in the following paragraphs. 


\section{Insert Shear Webs into Fixture}

The shear webs have to be put in place into the shear web fixture. A team can load a 50-meter-long shear web into the fixture in 15 minutes. A manufacturer may maintain that time with longer shear webs by increasing the number of workers. However, for this model, a reward/penalty of \pm 1 minute per meter per shear web above/below 50 meters is assumed.

For each web, the labor and the cycle time are estimated as

$$
\begin{gathered}
\text { Labor }=(0.25 \mathrm{hr}-0.0167 *(50-\text { Web Length }) * \# \text { Workers } \\
C T=(0.25 \mathrm{hr}-0.0167 *(50-\text { Web Length })
\end{gathered}
$$

\section{Dry Fit-Boundary Mark}

Once shear webs are into the shear web fixture, a check is typically conducted to verify that the assembly fits well with the lower skin and that bond gaps are within tolerance. The alignment and the thickness of the glue lines are areas of special concern. Marks are often used along the molds to place bond measuring media, such as clay balls. The cycle time of this process depends on the maturity of the production line, and in advanced facilities it can be skipped entirely. Nonetheless, to be generic the process is here modeled, assuming a rate of $60 \mathrm{~m} / \mathrm{hr} / \mathrm{worker}$.

$$
\begin{gathered}
\text { Labor }=\frac{\text { Webs Length }}{60 \mathrm{~m} / \mathrm{hr} / \text { worker }} \\
C T=\frac{\text { Labor }}{\# \text { Workers }}
\end{gathered}
$$

\section{Remove Nonsand Tape}

Nonsand tape is removed right before the gluing process. The first step consists of removing the nonsand tape. Here, the assumption is that each worker can remove $1 \mathrm{~m}$ of tape in 60 seconds. This means 60 meters in 1 hour. This process has to be performed first along the length of each shear web. Once the assembly is ready to be closed, the nonsand tape along the mold perimeter for both LP and HP sides is also removed. This model estimates the combined labor and cycle time for both shear webs and perimeter.

LP side:

$$
\begin{gathered}
\text { Labor }=\frac{\text { Webs Length }+ \text { Mold Perimeter }}{60 \mathrm{~m} / \mathrm{hr} / \text { worker }} \\
C T=\frac{\text { Labor }}{0.5 * \# \text { Workers }}
\end{gathered}
$$

HP side:

$$
\begin{gathered}
\text { Labor }=\frac{\text { Webs Length }+ \text { Mold Perimeter }}{60 \mathrm{~m} / \mathrm{hr} / \text { worker }} \\
C T=\frac{\text { Labor }}{0.5 * \# \text { Workers }}
\end{gathered}
$$




\section{Dispense Lower Adhesive}

A layer of adhesive is placed below each shear web. It is assumed that each worker conducts the operation at an average rate of $60 \mathrm{~m} / \mathrm{hr}$.

$$
\begin{gathered}
\text { Labor }=\frac{\text { Webs Length }}{60 \mathrm{~m} / \text { hr } / \text { worker }} \\
C T=\frac{\text { Labor }}{\# \text { Workers }}
\end{gathered}
$$

\section{Bond Shear Webs-Lower}

Once the adhesive is in place in the lower skin, the team of workers can place the shear webs in the shear web fixture onto the adhesive in the skin in 15 minutes.

$$
\begin{gathered}
\text { Labor }=0.25 \mathrm{hr} * \# \text { Workers } \\
C T=0.25 \mathrm{hr}
\end{gathered}
$$

\section{Fillet Shear Web Bonds}

One worker can then fillet 3 meters of bonding line per minute (i.e., $180 \mathrm{~m} / \mathrm{hr}$ ). Each shear web bond length has two sides to fillet.

$$
\begin{gathered}
\text { Labor }=2 * \frac{\text { Webs Length }}{180 \mathrm{~m} / \text { hr } / \text { worker }} \\
C T=\frac{\text { Labor }}{\# \text { Workers }}
\end{gathered}
$$

\section{Cure-Lower}

The curing of the shear web adhesive takes 2 hours and can proceed unsupervised.

$$
\begin{gathered}
\text { Labor }=0 \mathrm{hr} \\
C T=2 \mathrm{hr}
\end{gathered}
$$




\section{Remove Fixture}

After the curing, the team removes the clamps and disengages the shear web fixture in 15 minutes.

$$
\begin{gathered}
\text { Labor }=0.25 \mathrm{hr} * \# \text { Workers } \\
C T=0.25 \mathrm{hr}
\end{gathered}
$$

\section{Dry Fit-Upper}

It is assumed here that one worker can check the dry fit (using clay or other method) of $1 \mathrm{~m}$ of shear web in 4 minutes (i.e., $15 \mathrm{~m} / \mathrm{hr}$ ). The cycle time is governed here by the number of workers during the dry fit phase, plus the opening and closing time. The labor of opening and closing is, however, neglected.

$$
\begin{gathered}
\text { Labor }=2 * \frac{\text { Webs Length }}{15 \mathrm{~m} / \text { hr } / \text { worker }} \\
C T=\frac{\text { Labor }}{\# \text { Workers }}
\end{gathered}
$$

\section{Shear Web Height Rework}

If the dry fit results are off, then a significant amount of labor and cycle time could be added to the assembly process. In the early stages of manufacturing, this could be substantial. However, this model assumes a mature bonding process and 0 hours of labor and cycle time for rework.

\section{Dispense Upper Perimeter Adhesive}

The adhesive on the upper edges of the shear webs and on the blade outer perimeter is then dispensed.

$$
\begin{gathered}
\text { Labor }=\frac{\text { Webs Length }+ \text { Mold Perimeter }}{60 \mathrm{~m} / \text { hr } / \text { worker }} \\
C T=\frac{\text { Labor }}{\# \text { Workers }}
\end{gathered}
$$

\section{Close Mold}

The mold is closed using a hinge system, which is assumed to take a set time of approximately 5 minutes (i.e., 0.0833 hours). The cycle time is fixed by the activity time. The team assures that the mold closes properly, with one worker operating the power hinge assembly.

$$
\begin{gathered}
\text { Labor }=0.0833 \mathrm{hr} * \# \text { Workers } \\
C T=0.0833 \mathrm{hr}
\end{gathered}
$$




\section{Install Shear Clips}

Wet layup shear clips are assumed to cover $50 \%$ of the length of the shear webs on both sides of the upper and lower bonds. A wet layup on the inner skin root bonds for $10 \%$ of the span of the blade is also assumed. The model assumes that each worker of the team installs 4 meters of clips per hour. This includes the placement and rolling out air voids.

$$
\begin{gathered}
\text { Labor }=\frac{4 * 50 \% * \text { Webs Length }+2 * 10 \% * \text { Blade Length }}{4 \mathrm{~m} / \text { hr } / \text { worker }} \\
C T=\frac{\text { Labor }}{\# \text { Workers }}
\end{gathered}
$$

\section{Cure-Entire}

The final curing is assumed to last 2 hours after the mold is closed, where the process can typically proceed unsupervised.

$$
\begin{gathered}
\text { Labor }=0 \mathrm{hr} \\
C T=2 \mathrm{hr}
\end{gathered}
$$

\section{Open Mold}

Finally the mold is reopened, where one worker operates the hinge assembly and cycle time is fixed by an activity time of 5 minutes.

$$
\begin{gathered}
\text { Labor }=0.0833 \mathrm{hr} \\
C T=0.0833 \mathrm{hr}
\end{gathered}
$$

\subsection{Demold}

The assembly process described in Section 3.3 is followed by the demolding of the whole blade. This requires these four substeps:

- Cool-down

- Place lift straps

- Transfer to blade cart

- Move blade to finishing area.

This process is mostly cycle time driven and increasing team size has little to no benefit. A team of four is assumed. 


\section{Cool-Down}

A uniform cool-down period for all blades is assumed to be 1 hour. This may have to be reevaluated for very large blades (i.e., blades longer than 100 meters). However, design trends suggest that large blades do not have significantly increased laminate thicknesses. The cool-down period is therefore held constant. No personnel are typically required for the cool-down period.

$$
\begin{gathered}
\text { Labor }=1 \mathrm{hr} \\
C T=1 \mathrm{hr}
\end{gathered}
$$

The preparation of the lift straps, the movement of the cranes, and so on, are all completed during the cool-down period, so as to not adversely affect cycle time. This model does not capture the labor hours required for that work, but it is important to know that this would not affect the model cycle time either way.

\section{Place Lift Straps}

All megawatt-size blades require a minimum of 30 minutes to position lift straps (lift root end of blade, position root strap, lift tip of blade, position tip strap, attach straps to crane). A premium of 0.5 minutes per extra meter of blade length above $40 \mathrm{~m}$ is assumed.

$$
\begin{array}{r}
\text { Labor }= \begin{cases}0.5 \mathrm{hr} * 4 \text { Workers }, & \begin{array}{l}
\text { if Blade Length } \leq 40 \mathrm{~m} \\
\left(0.5 \mathrm{hr}+(\text { Blade Length }-40 \mathrm{~m}) * \frac{0.5}{60} \mathrm{~m} / \mathrm{hr}\right) * 4 \text { Workers, }
\end{array} \\
\text { else }\end{cases} \\
C T= \begin{cases}0.5 \mathrm{hr}, & \text { if Blade Length } \leq 40 \mathrm{~m} \\
\left(0.5 \mathrm{hr}+(\text { Blade Length }-40 \mathrm{~m}) * \frac{0.5}{60} \mathrm{~m} / \mathrm{hr}\right), & \text { else }\end{cases}
\end{array}
$$

\section{Transfer to Blade Cart}

All megawatt-size blades and above require a minimum of 15 minutes to be transferred to carts. However, because of extra complexity with larger blade lengths, a premium of 1 minute per extra meter of blade length above $60 \mathrm{~m}$ should be added.

$$
\begin{array}{r}
\text { Labor }= \begin{cases}0.25 h r * 4 \text { Workers }, & \begin{array}{l}
\text { if Blade Length } \leq 60 \mathrm{~m} \\
\left(0.25 \mathrm{hr}+(\text { Blade Length }-60 \mathrm{~m}) * \frac{1}{60} \mathrm{~m} / \mathrm{hr}\right) * 4 \text { Workers, }
\end{array} \\
\text { else }\end{cases} \\
C T= \begin{cases}0.25 \mathrm{hr}, & \text { if Blade Length } \leq 60 \mathrm{~m} \\
\left(0.25 \mathrm{hr}+(\text { Blade Length }-60 \mathrm{~m}) * \frac{1}{60} \mathrm{~m} / \mathrm{hr}\right), & \text { else }\end{cases}
\end{array}
$$




\section{Move Blade to Finishing Area}

Finally, blades are moved to the finishing area. Megawatt-size blades require a minimum of 10 minutes to be moved, with a premium of $1 / 3$ minute per extra meter of blade length above $60 \mathrm{~m}$ due to extra complexity with larger blade lengths.

$$
\begin{aligned}
& \text { Labor }= \begin{cases}\frac{10}{60} h r * 4 \text { Workers }, & \text { if Blade Length } \leq 60 m \\
\left(\frac{10}{60} h r+(\text { Blade Length }-60 m) * \frac{1 / 3}{60} m / h r\right) * 4 \text { Workers, }, & \text { else }\end{cases} \\
& C T= \begin{cases}\frac{10}{60} h r, & \text { if Blade Length } \leq 60 m \\
\left(\frac{10}{60} h r+(\text { Blade Length }-60 m) * \frac{1 / 3}{60} m / h r\right), & \text { else }\end{cases}
\end{aligned}
$$

\subsection{Trim}

Trimming is the process of cutting the excess flash along the blade outer bond line. Flash is a term used to describe any material that sticks out laterally from the perimeter bond lines of the blade. The flash can consist of excess resin, fibers, and adhesive that has been squeezed out (or intentionally placed) outside of the known trim lines for the blade. Trimming consists of three steps:

- Move the blade into the trim booth

- Trim the blade

- Move the blade out of the trim booth.

\section{Move Blade into the Trim Booth}

Three workers can move the blade into and out of the trim booth in 30 minutes. Please note that this number of workers and the cycle time may be reduced with cart tracks and/or automated pulling systems. Because of the straight line move, no extra time is added for very large blades.

$$
\begin{gathered}
\text { Labor }=0.5 \mathrm{hr} * 3 \text { Workers } \\
C T=0.5 \mathrm{hr}
\end{gathered}
$$

\section{Trim Blade}

Using power tools, one worker can trim at a rate of $10 \mathrm{~m} / \mathrm{hr}$, including rough cut and finer trimming. This rate includes a buffer time to account for mating irregularities and for extra attention, including the use of a fixture, at the blade tip. This model assumes a team of six workers trimming the blade. The cycle time can be increased or decreased by altering the size of this team.

$$
\begin{gathered}
\text { Labor }=\frac{\text { Blade Perimeter }}{10 \mathrm{~m} / \text { hr } / \text { worker }} \\
C T=\frac{\text { Labor }}{6 \text { Workers }}
\end{gathered}
$$


Move Blade out of the Trim Booth

Exactly as with the moving into the booth, moving the blade out of the trim booth requires 30 minutes and the work of three workers.

$$
\begin{gathered}
\text { Labor }=0.5 \mathrm{hr} * 3 \text { Workers } \\
C T=0.5 \mathrm{hr}
\end{gathered}
$$

\subsection{Overlay}

Numerical models of blades do not always include overlay. Overlay consists of a few extra plies of composite laminate placed at a portion of the span to strengthen the blade structure in crucial sections. Overlay is not included here in the cost or weight of materials. However, an estimate of overlay labor is included in this labor model. This model assumes a $20 \%$ span of overlay coverage.

The steps to apply and cure the overlay are:

- Move blade to station

- Rotate blade 90 degrees

- Place staging

- Repair overbite/underbite

- Install overlay

- Vacuum bag overlay

- Cure overlay

- Remove vacuum bag.

\section{Move Blade to Station}

A crew of three workers moves the blade from the previous station (trim) to the overlay station in 15 minutes. Similar to the movements of the blades described earlier, this number of workers and the cycle time could be reduced with cart tracks and/or automated pulling systems. No extra time is added for very large blades.

$$
\begin{gathered}
\text { Labor }=0.25 \mathrm{hr} * 3 \text { Workers } \\
C T=0.25 \mathrm{hr}
\end{gathered}
$$




\section{Rotate Blade}

Typically, blades need to be rotated by 90 degrees around the pitch axis for the application of the overlay. Three workers can rotate a blade up to 40 meters in length in 30 minutes. A premium of 0.5 minutes per extra meter of blade length over 40 meters is added. This includes switching the blade carts from flap style to edge style.

$$
\begin{gathered}
\text { Labor }= \begin{cases}0.5 \mathrm{hr} * 3 \text { Workers }, & \begin{array}{l}
\text { if Blade Length } \leq 40 \mathrm{~m} \\
\left(0.5 \mathrm{hr}+(\text { Blade Length }-40 \mathrm{~m}) * \frac{0.5}{60} \mathrm{~m} / \mathrm{hr}\right) * 3 \text { Workers, }
\end{array} \\
\text { else }\end{cases} \\
C T= \begin{cases}0.5 \mathrm{hr}, & \text { if Blade Length } \leq 40 \mathrm{~m} \\
\left(0.5 \mathrm{hr}+(\text { Blade Length }-40 \mathrm{~m}) * \frac{0.5}{60} \mathrm{~m} / \mathrm{hr}\right), & \text { else }\end{cases}
\end{gathered}
$$

\section{Place Staging}

A set time of 15 minutes is assumed to move staging into place to perform overlay. A six-worker team participates. No difference is included for blade size.

$$
\begin{gathered}
\text { Labor }=0.25 \mathrm{hr} * 6 \text { Workers } \\
C T=0.25 \mathrm{hr}
\end{gathered}
$$

\section{Repair Overbite/Underbite}

The model does not include any time or labor for overbite and underbite repair. However, this step is included here as a placeholder.

\section{Install Overlay}

Because of a lack of a detailed structural model for the overlay, this model assumes that the inner $20 \%$ of blade span receives overlay (both leading- and trailing-edge), with eight layers of overlay and an average taper of 0.5 meters per layer per end. The calculation of ply lengths ignores the contour of leading- and trailing-edge.

A 12-worker team is assumed, with an overall installation rate of $4 \mathrm{~m}$ of overlay ply/hr/worker.

$$
\begin{gathered}
\text { Labor }=\frac{\text { Total Overlay Ply Length }}{4 \mathrm{~m} / \text { hr } / \text { worker }} \\
C T=\frac{\text { Labor }}{12 \text { Workers }}
\end{gathered}
$$




\section{Vacuum Bag Overlay}

Two teams of three workers each can install a peel-ply, Tacky Tape and vacuum bag, and pull vacuum at an approximate rate of $1 \mathrm{~m}$ of overlay length in 2 minutes, this makes $60 \mathrm{~m} / \mathrm{hr}$ for the two teams.

$$
\begin{gathered}
\text { Labor }=2 * 20 \% * \frac{\text { Blade Length }}{60 \mathrm{~m} / \mathrm{hr}} * 6 \text { Workers } \\
C T=2 * 20 \% * \frac{\text { Blade Length }}{60 \mathrm{~m} / \mathrm{hr}}
\end{gathered}
$$

\section{Cure of Overlay}

Assuming that the resin catalyzes and cures in 1 hour and that in the meanwhile the six-worker team cleans the area from wet layup during the cure time, labor and cycle time sums up to:

$$
\begin{gathered}
\text { Labor }=1 \mathrm{hr} * 6 \text { Workers } \\
C T=1 \mathrm{hr}
\end{gathered}
$$

\section{Remove Vacuum Bag}

Finally, a team of three workers can remove $1 \mathrm{~m}$ of vacuum bags of overlay in 30 seconds, therefore working at a hourly rate of $180 \mathrm{~m} / \mathrm{hr}$.

$$
\begin{gathered}
\text { Labor }=20 \% * \frac{\text { Blade Length }}{180 \mathrm{~m} / \mathrm{hr}} * 3 \text { Workers } \\
C T=20 \% * \frac{\text { Blade Length }}{180 \mathrm{~m} / \mathrm{hr}}
\end{gathered}
$$

\subsection{Postcure}

The postcure step is a thermal process to make sure that all components have the resin and the adhesive fully cured. Five different steps are distinguished:

- Place blade in oven carts

- Move blade into oven

- Postcure dwell

- Move blade out of oven

- Cool-down dwell. 


\section{Place Blade in Oven Carts}

Three workers can place a blade into the oven carts. The blade can have the same position as in the overlay station. Up to 40 meters in length, a cycle time of 15 minutes is assumed. Above this blade length, a premium of 0.25 minutes per extra meter of blade length should be considered.

$$
\begin{aligned}
& \text { Labor }= \begin{cases}0.25 h r * 3 \text { Workers }, & \text { if Blade Length } \leq 40 \mathrm{~m} \\
\left(0.25 h r+(\text { Blade Length }-40 \mathrm{~m}) * \frac{0.25}{60} \mathrm{~m} / \mathrm{hr}\right) * 3 \text { Workers, }, & \text { else }\end{cases} \\
& C T= \begin{cases}0.25 h r, & \text { if Blade Length } \leq 40 \mathrm{~m} \\
\left(0.25 \mathrm{hr}+(\text { Blade Length }-40 \mathrm{~m}) * \frac{0.25}{60} \mathrm{~m} / \mathrm{hr}\right), & \text { else }\end{cases}
\end{aligned}
$$

\section{Move Blade into Oven}

Two workers can move the blade into and out of the oven in 10 minutes. This time assumes that the blade oven carts are on tracks and use either a pulley or forklift to propel the blade carts. Time also includes the setting of the oven controls.

$$
\begin{gathered}
\text { Labor }=\frac{10}{60} h r * 2 \text { Workers } \\
C T=\frac{10}{60} h r
\end{gathered}
$$

\section{Postcure Dwell}

A total oven time (ramp up, dwell, and ramp down) of 8 hours is assumed, where no worker is required to supervise the operation.

$$
\begin{gathered}
\text { Labor }=0 \mathrm{hr} \\
C T=8 \mathrm{hr}
\end{gathered}
$$

\section{Move Blade out of Oven}

Moving the blade out of the oven takes the same labor and cycle time as the move-in step.

$$
\begin{gathered}
\text { Labor }= \begin{cases}0.25 \mathrm{hr} * 3 \text { Workers }, & \begin{array}{l}
\text { if Blade Length } \leq 40 \mathrm{~m} \\
\left(0.25 \mathrm{hr}+(\text { Blade Length }-40 \mathrm{~m}) * \frac{0.25}{60} \mathrm{~m} / \mathrm{hr}\right) * 3 \text { Workers, }
\end{array} \\
\text { else }\end{cases} \\
C T= \begin{cases}0.25 \mathrm{hr}, & \text { if Blade Length } \leq 40 \mathrm{~m} \\
\left(0.25 \mathrm{hr}+(\text { Blade Length }-40 \mathrm{~m}) * \frac{0.25}{60} \mathrm{~m} / \mathrm{hr}\right), & \text { else }\end{cases}
\end{gathered}
$$




\section{Cool-Down Dwell}

The blade should cool-down for a period of 1 hour once removed from the oven. No personnel are required.

$$
\begin{gathered}
\text { Labor }=0 \mathrm{hr} \\
C T=1 \mathrm{hr}
\end{gathered}
$$

\subsection{Root Cut and Drill}

At this stage of manufacturing, blades undergo cutting and drilling for their root holes. This process can be subdivided into six steps:

- Move blade/place in saddles

- Check level/point of reference

- Machine trim blade root

- Clear trim excess

- Machine cut axial and radial holes

- Clear drill excess.

\section{Move Blade/Place in Saddles}

Similar to previously described movements of blades via carts, it is assumed here that a team of three workers can lift a blade up to 40 meters in length from the previous station (oven) and place it into the root trim saddles in 10 minutes. A premium of 0.5 minutes per extra meter of blade length over 40 meters is added.

$$
\begin{gathered}
\text { Labor }= \begin{cases}\frac{10}{60} h r * 3 \text { Workers }, & \begin{array}{l}
\text { if Blade Length } \leq 40 m \\
\left(\frac{10}{60} h r+(\text { Blade Length }-40 m) * \frac{0.5}{60} m / h r\right) * 3 \text { Workers, }
\end{array} \\
\text { else }\end{cases} \\
C T= \begin{cases}\frac{10}{60} h r \\
\left(\frac{10}{60} h r+(\text { Blade Length }-40 m) * \frac{0.5}{60} m / h r\right), & \text { else Blade Length } \leq 40 m\end{cases}
\end{gathered}
$$

\section{Check Level/Point of Reference}

Two workers can then check the blade level and the reference, and adjust as required, in an average time of 20 minutes.

$$
\begin{gathered}
\text { Labor }=\frac{20}{60} h r * 2 \text { Workers } \\
C T=\frac{20}{60} h r
\end{gathered}
$$


Trim Blade Root

The cutting machine can cut the blade root at a rate of $1 \mathrm{~m}$ of root circumference per 10 minutes (i.e., $6 \mathrm{~m} / \mathrm{hr}$ ).

$$
\begin{gathered}
\text { Labor }=\frac{\text { Root Circumf. }}{6 \mathrm{~m} / \mathrm{hr}} * 2 \text { Workers } \\
C T=\frac{\text { Root Circumf. }}{6 \mathrm{~m} / \mathrm{hr}}
\end{gathered}
$$

\section{Clear Trim Excess}

The crew of two can then clear the trimmed root section from the machine area in 15 minutes.

$$
\begin{gathered}
\text { Labor }=0.25 h r * 2 \text { Workers } \\
C T=0.25 h r
\end{gathered}
$$

\section{Machine Cut Axial and Radial Holes}

The root cutting machine can cut two holes at once, one axial and one radial on the opposite sides of the root. The assumption is that it takes the same time to drill each hole, namely 2 minutes. This time is then multiplied by the number of root bolts.

$$
\begin{gathered}
\text { Labor }=\frac{2}{60} h r * \text { Number Root Bolts } * 2 \text { Workers } \\
C T=\frac{2}{60} h r * \text { Number Root Bolts }
\end{gathered}
$$

\section{Clear Drill Excess}

Finally, the team of two workers clears the excess from the drilling from the machine area in 15 minutes.

$$
\begin{gathered}
\text { Labor }=0.25 h r * 2 \text { Workers } \\
C T=0.25 h r
\end{gathered}
$$

\subsection{Root Fasteners Installation}

Once holes are drilled, the barrel nuts can be installed. This process is subdivided into three substeps:

- Move blade/place in carts

- Install barrel nuts

- Apply root band. 


\section{Move Blade/Place in Carts}

A team of three workers can lift a blade up to 40 meters in length from the previous station (root drill) and place it into the root hardware install carts in 10 minutes. A premium of 0.5 minutes per extra meter of blade length over 40 meters is added.

$$
\begin{gathered}
\text { Labor }= \begin{cases}\frac{10}{60} h r * 3 \text { Workers }, & \begin{array}{l}
\text { if Blade Length } \leq 40 m \\
\left(\frac{10}{60} h r+(\text { Blade Length }-40 m) * \frac{0.5}{60} m / h r\right) * 3 \text { Workers, }
\end{array} \\
\text { else }\end{cases} \\
C T= \begin{cases}\frac{10}{60} h r, & \text { if Blade Length } \leq 40 \mathrm{~m} \\
\left(\frac{10}{60} h r+(\text { Blade Length }-40 \mathrm{~m}) * \frac{0.5}{60} \mathrm{~m} / \mathrm{hr}\right), & \text { else }\end{cases}
\end{gathered}
$$

\section{Install Barrel Nuts}

One worker can install one barrel nut, including preparation, filling, and installation, in 2.5 minutes (i.e., a rate of 24 nuts/hr).

$$
\begin{gathered}
\text { Labor }=\frac{\text { Number Root bolts }}{24 \# / h r} \\
C T=\frac{\text { Labor }}{2 \text { Workers }}
\end{gathered}
$$

\section{Apply Root Band}

Finally, a root band can be installed by two workers at a rate of $1 \mathrm{~m}$ per 10 minutes, $6 \mathrm{~m} / \mathrm{hr}$, along the root circumference.

$$
\begin{gathered}
\text { Labor }=\frac{\text { Root circumf. }}{6 \mathrm{~m} / \mathrm{hr}} * 2 \text { Workers } \\
C T=\frac{\text { Root circumf. }}{6 \mathrm{~m} / \mathrm{hr}}
\end{gathered}
$$

\subsection{Surface Preparation}

The process of preparing the outer surface involves two steps:

- Move blade carts to area

- Perform surface preparation. 


\section{Move Blade Carts to Area}

The assumption is that two workers can move the blade to the surface preparation area in 10 minutes. This time assumes that the blade carts are on tracks and use either a pulley or forklift to propel the blade carts.

$$
\begin{gathered}
\text { Labor }=\frac{10}{60} h r * 2 \text { Workers } \\
C T=\frac{10}{60} h r
\end{gathered}
$$

\section{Perform Surface Preparation}

A whole crew of eight workers is assumed to conduct the surface preparation, which means sanding and filling pinholes and rough spots. One worker can prepare $1 \mathrm{~m}^{2}$ in 10 minutes, which converts to $6 \mathrm{~m}^{2} / \mathrm{hr}$.

$$
\begin{gathered}
\text { Labor }=\frac{\text { Blade Outer Surface }}{6 \mathrm{~m}^{2} / \mathrm{hr}} * 8 \text { Workers } \\
C T=\frac{\text { Blade Outer Surface }}{6 \mathrm{~m}^{2} / \mathrm{hr}}
\end{gathered}
$$

\subsection{Paint}

The exterior surface of a wind turbine blade is painted at the end of the manufacturing process to help with weatherrelated wear of the materials and provide a smooth surface finish. Although automated painting decreases cycle time and labor hours (and possibly increases quality), as of now this model assumes hand painting. Here, these five substeps are assumed:

- Move blade carts into paint booth

- Apply primer

- Cure/tackify

- Apply top coat

- Cure.

\section{Move Blade Carts into Paint Booth}

Two workers can move the blade into the paint booth in 10 minutes. This time assumes that the blade carts are on tracks and use either a pulley or forklift to propel the blade carts.

$$
\begin{gathered}
\text { Labor }=\frac{10}{60} h r * 2 \text { Workers } \\
C T=\frac{10}{60} h r
\end{gathered}
$$




\section{Apply Primer}

Before painting the blade, a sublayer, called primer, is applied. This helps the top coat to stick to the blade. Four workers are on a paint team, whose size is typically governed by the number of paint guns and the space of working inside the paint booth. One worker can spray $1 \mathrm{~m}^{2}$ of primer or paint in 30 seconds. This means a rate of $480 \mathrm{~m}^{2} / \mathrm{hr}$ for the four-worker team.

$$
\begin{gathered}
\text { Labor }=\frac{\text { Blade Outer Surface }}{480 \mathrm{~m}^{2} / \mathrm{hr}} * 4 \text { Workers } \\
C T=\frac{\text { Blade Outer Surface }}{480 \mathrm{~m}^{2} / \mathrm{hr}}
\end{gathered}
$$

\section{Cure/Tackify}

For the curing of the primer, an elevated temperature dwell time of 1 hour to partially cure and tackify the primer is assumed. The four workers use the dwell times to either prepare the paint and equipment or clean up the paint and equipment. Therefore, the model assumes four workers working during the dwell times.

$$
\begin{gathered}
\text { Labor }=1 h r * 4 \text { Workers } \\
C T=1 h r
\end{gathered}
$$

\section{Apply Top Coat}

The top coat is then applied by the four-worker crew:

$$
\begin{gathered}
\text { Labor }=\frac{\text { Blade Outer Surface }}{480 \mathrm{~m}^{2} / \mathrm{hr}} * 4 \text { Workers } \\
C T=\frac{\text { Blade Outer Surface }}{480 \mathrm{~m}^{2} / \mathrm{hr}}
\end{gathered}
$$

\section{Cure}

Finally, a curing process starts. An elevated temperature dwell time of 3 hours to cure the paint is assumed. During the long cycle time, workers are assumed busy. This is a realistic assumption because workers conducting the painting process are typically very specialized and painting is an especially intensive process. As as result, workers are usually not moved to other activities.

$$
\begin{gathered}
\text { Labor }=3 h r * 4 \text { Workers } \\
C T=3 h r
\end{gathered}
$$




\subsection{Surface Finishing}

The surface finishing process consists of a visual inspection and a refinishing of pinholes, drips, and so on. Two steps are assumed:

- Move blade carts to area

- Perform surface inspection/finish.

Move Blade Carts to Area

As for previous movements of the blade, the assumption is that two workers can move the blade to the surface finish area in 10 minutes.

$$
\begin{gathered}
\text { Labor }=\frac{10}{60} h r * 2 \text { Workers } \\
C T=\frac{10}{60} h r
\end{gathered}
$$

\section{Perform Surface Inspection/Finish}

One worker can then inspect and finish $1 \mathrm{~m}^{2}$ of outer blade surface in two minutes (i.e., $30 \mathrm{~m}^{2} / \mathrm{hr}$ ). This rate also includes the priming and painting of the area where the paint booth saddle was located.

$$
\begin{gathered}
\text { Labor }=\frac{\text { Blade Outer Surface }}{30 \mathrm{~m}^{2} / \mathrm{hr}} * 3 \text { Workers } \\
C T=\frac{\text { Blade Outer Surface }}{30 \mathrm{~m}^{2} / \mathrm{hr}}
\end{gathered}
$$

\subsection{Weight and Balance}

One of the last steps during the manufacturing of a blade is to weigh and balance it. This process consists of six steps:

- Move blade/place in saddles

- Check balance

- Drill holes into balance boxes

- Mix balance box filler

- Pump filler into balance boxes

- Plug balance box holes. 


\section{Move Blade/Place in Saddles}

Three workers can lift a blade up to 40 meters in length from the previous station (surface finish) and place it into the weight and balance saddles in 10 minutes. A premium of 0.5 minutes per extra meter of blade length over 40 meters is, as previously, assumed.

$$
\begin{gathered}
\text { Labor }= \begin{cases}\frac{10}{60} h r * 3 \text { Workers }, & \begin{array}{l}
\text { if Blade Length } \leq 40 m \\
\left(\frac{10}{60} h r+(\text { Blade Length }-40 m) * \frac{0.5}{60} m / h r\right) * 3 \text { Workers, }
\end{array} \\
\text { else }\end{cases} \\
C T= \begin{cases}\frac{10}{60} h r, & \text { if Blade Length } \leq 40 \mathrm{~m} \\
\left(\frac{10}{60} h r+(\text { Blade Length }-40 m) * \frac{0.5}{60} \mathrm{~m} / \mathrm{hr}\right), & \text { else }\end{cases}
\end{gathered}
$$

\section{Check Balance}

Two workers can check the blade balance level and calculate the required weight of fill in each balance box in an average time of 15 minutes.

$$
\begin{gathered}
\text { Labor }=0.25 \mathrm{hr} * 3 \text { Workers } \\
C T=0.25 \mathrm{hr}
\end{gathered}
$$

\section{Drill Holes into Balance Boxes}

One worker can drill a hole in 5 minutes. This time includes the preparation time for the equipment. This means an average of two holes every 10 minutes. Labor hours for this task are calculated with two workers.

$$
\begin{gathered}
\text { Labor }=\frac{10}{60} h r * 2 \text { Workers } \\
C T=\frac{10}{60} h r
\end{gathered}
$$

\section{Mix Balance Box Filler}

Two workers can mix the average required filler for the two balance boxes in 0.5 hours.

$$
\begin{gathered}
\text { Labor }=0.5 h r * 2 \text { Workers } \\
C T=0.5 h r
\end{gathered}
$$




\section{Pump Filler into Balance Boxes}

The two workers can then pump one balance box with the average required filler in 30 minutes (i.e., 1 hour for 2 balance boxes). This includes preparing the equipment, pumping, and cleaning the equipment.

$$
\begin{gathered}
\text { Labor }=1 \mathrm{hr} * 2 \text { Workers } \\
C T=1 \mathrm{hr}
\end{gathered}
$$

\section{Plug Balance Box Holes}

Finally, the two-worker team can plug a balance box hole, including touch-up work, in 20 minutes. The two holes can be plugged in 40 minutes.

$$
\begin{gathered}
\text { Labor }=\frac{40}{60} h r * 2 \text { Workers } \\
C T=\frac{40}{60} h r
\end{gathered}
$$

\subsection{Inspection}

A final inspection step is conducted, with two steps:

- Move blade/place in shipping saddles

- Perform final inspection

\section{Move Blade/Place in Shipping Saddles}

Three workers can lift a blade up to 40 meters in length from the previous station (weight and balance) and place it into the final shipping saddles in 20 minutes. A premium of 0.5 minutes per extra meter of blade length over 40 meters is added.

$$
\begin{gathered}
\text { Labor }= \begin{cases}\frac{20}{60} h r * 3 \text { Workers }, & \begin{array}{l}
\text { if Blade Length } \leq 40 m \\
\left(\frac{20}{60} h r+(\text { Blade Length }-40 m) * \frac{0.5}{60} m / h r\right) * 3 \text { Workers, }
\end{array} \\
\text { else }\end{cases} \\
C T= \begin{cases}\frac{20}{60} h r, & \text { if Blade Length } \leq 40 \mathrm{~m} \\
\left(\frac{20}{60} h r+(\text { Blade Length }-40 \mathrm{~m}) * \frac{0.5}{60} \mathrm{~m} / \mathrm{hr}\right), & \text { else }\end{cases}
\end{gathered}
$$




\section{Perform Final Inspection}

One worker can then perform the final inspection of $1 \mathrm{~m}^{2}$ in 10 seconds (i.e., $360 \mathrm{~m}^{2} / \mathrm{hr}$ ). A team of two is assumed.

$$
\begin{gathered}
\text { Labor }=\frac{\text { Blade Outer Surface }}{360 \mathrm{~m}^{2} / \mathrm{hr}} * 2 \text { Workers } \\
C T=\frac{\text { Blade Outer Surface }}{360 \mathrm{~m}^{2} / \mathrm{hr}}
\end{gathered}
$$

\subsection{Shipping Preparation}

The last step in blade manufacturing is the preparation of the blade for shipping. In this model, this is broken up in seven substeps conducted by a team of two workers, except for the last movement of the blade where three workers are assumed as necessary:

- Install final root bolts

- Install root plate

- Connect lightning protection system

- Install root cover

- Install 0 deg pitch plate

- Apply blade serial number

- Remove blade from factory.

\section{Install Final Root Bolts}

One worker can install one root bolt in 30 seconds, which means 120 bolts/hr. Please note that the barrel nuts are already placed; see Section 3.9.

$$
\begin{gathered}
\text { Labor }=\frac{\text { Number Root Bolts }}{120 \# / h r} \\
C T=\frac{\text { Number Root Bolts }}{120 \# / h r} / 2 \text { Workers }
\end{gathered}
$$

\section{Install Root Plate}

A typical root plate can be installed in 0.4 hour.

$$
\begin{gathered}
\text { Labor }=0.4 h r * 2 \text { Workers } \\
C T=0.4 h r
\end{gathered}
$$




\section{Connect Lightning Protection System}

A typical lightning protection system can be connected in 30 minutes.

$$
\begin{gathered}
\text { Labor }=0.5 h r * 2 \text { Workers } \\
C T=0.5 h r
\end{gathered}
$$

Install Root Cover

A typical root cover can be installed in 15 minutes.

$$
\begin{gathered}
\text { Labor }=0.25 \mathrm{hr} * 2 \text { Workers } \\
C T=0.25 \mathrm{hr}
\end{gathered}
$$

Install 0 deg Pitch Plate

The 0 degrees pitch plate can be installed in 10 minutes.

$$
\begin{gathered}
\text { Labor }=\frac{10}{60} h r * 2 \text { Workers } \\
C T=\frac{10}{60} h r
\end{gathered}
$$

\section{Apply Blade Serial Number}

The blade serial number plate can be installed in 20 minutes.

$$
\begin{gathered}
\text { Labor }=\frac{20}{60} h r * 2 \text { Workers } \\
C T=\frac{20}{60} h r
\end{gathered}
$$




\section{Remove Blade from Factory}

Finally, three workers can remove a blade up to 50 meters in length from the factory and place it into storage in 30 minutes. A premium of 0.25 minutes per extra meter of blade length over 50 meters is assumed.

$$
\begin{array}{r}
\text { Labor }= \begin{cases}0.5 \mathrm{hr} * 3 \text { Workers }, & \begin{array}{l}
\text { if Blade Length } \leq 50 \mathrm{~m} \\
\left(0.5 \mathrm{hr}+(\text { Blade Length }-50 \mathrm{~m}) * \frac{0.25}{60} \mathrm{~m} / \mathrm{hr}\right) * 3 \text { Workers, }
\end{array} \\
\text { else }\end{cases} \\
C T= \begin{cases}0.5 \mathrm{hr}, & \text { if Blade Length } \leq 50 \mathrm{~m} \\
\left(0.5 \mathrm{hr}+(\text { Blade Length }-50 \mathrm{~m}) * \frac{0.25}{60} \mathrm{~m} / \mathrm{hr}\right), & \text { else }\end{cases}
\end{array}
$$




\section{Virtual Factory}

To compute an overall blade cost, including indirect capital costs, a virtual model of a manufacturing facility is generated. The model is parametric and it is built based on various blade characteristics.

To start, the model estimates the amount of parallel processes taking place simultaneously at each process station. In wind turbine blade manufacturing, this estimate is usually driven by two main parameters governing the whole factory:

- The number of blades that should be manufactured yearly

- The amount of sets of skin molds (low and high pressure).

The first parameter is mostly dictated by market considerations and wind turbine manufacturers have very small as well as very large factories installed in different locations worldwide. This model imagines a goal of 1,000 blades per year, although users can easily edit this value to represent their needs. The second parameter is also very important because of the high cost of the molds, as discussed in Section 3 and later in Section 4.5. These are assumed fully operational for 24 hours (three shifts) for a user-defined number of days per year. The default value assumed in this model is 250 days, as blade manufacturing facilities often work on 24-hour shifts from Monday to Friday, use Saturday to finish uncompleted tasks, and are closed on Sunday. In addition, factories are closed a couple of weeks per year for scheduled maintenance. The number of sets of half-molds is then estimated as

$$
\# \text { Sets Skin Molds }=\left\lceil\frac{\# \text { Blades } * \text { Gating CT }}{\# \text { Days } * 24 \mathrm{hr}} * \frac{1}{1-\text { Rejection Rate }}\right\rceil
$$

Where Gating $C T$ is assumed equal to 24 hours, and the rejection rate is the cumulative rate of defected products building up from one operation to the other and that is included within the bill of materials as scrap factor. In this formula, the rejection rate sums up the rates of the processes accounting for the gating time (i.e., the assembly), the infusion, and the demolding taking place at the main mold.

It should be highlighted that in reality the 24-hour cycle is something that is aspired to, but rarely achieved. For blades longer than 60 meters, the added walking time of people-constrained activities is making the 24-hour cycle extremely challenging. While this may impact cycle time more than labor, the subsequent impact is on the size of facilities needed to make desire output levels and/or output per mold per year.

This said, for simplicity this model assumes that the cycle time can be limited to 24 hours. The amount of parallel processes running for infusion of low- and high-pressure skins (Section 3.2), main assembly (Section 3.3), and demolding (Section 3.4), is then equal to the number of sets of molds. Four sets of molds are necessary to meet the annual production target. All other processes are then planned according to this production cadence. This is expressed by the following equation:

$$
\# \text { processes }=\text { round up }\left(\# \text { Sets Skin Molds } * \frac{C T}{\text { Gating } C T} * \frac{1}{1-\text { Rejection Rate }}\right)
$$

Based on this virtual factory model, the various cost components of the model include the following, each of which is explained in the following sections.

1. Direct labor

2. Overhead

3. Building

4. Utility 
5. Tooling

6. Equipment

7. Maintenance

8. Capital.

\subsection{Direct Labor Costs}

The labor costs associated with each blade manufacturing process are estimated with the formula:

$$
\text { Labor Cost }=\frac{\text { Labor Time } * \text { Wage } *(1+\text { Benefits })}{(1-\text { Avg Downtime }) *(1-\text { Rejection Rate })}
$$

The parameters Wage, Benefits, Avg Downtime, and Rejection Rate are user-defined inputs specific to each operation:

- Wage-Pay rate per hour for unskilled workers. The default value is $\$ 20 / \mathrm{hr}$. Please note that the model does not include the use of skilled laborers in certain operations, although its inclusion would be easy to implement.

- Benefits-The percentage of benefits on wage. The default value is $30.4 \%$ (Anon. 2018).

- Avg Downtime-Average downtime workers and the equipment have. The default value is 20\% (Anon. 2018).

- Rejection Rate-Cumulative rejection rate from one operation to the other. The default value for the rejection rate of each process is here assumed equal to $0.25 \%$.

The total labor cost per blade is the sum of the labor costs of each operation.

\subsection{Overhead Costs}

Standard processes estimate an overhead on the direct labor costs. This model assumes overhead as a percentage of the labor costs:

$$
\text { Overhead Costs }=\text { Labor Cost } * \% \text { Overhead }
$$

The percentage is user defined. The default value is here assumed to be $30 \%$ (Anon. 2018).

\subsection{Building Costs}

The model estimates the costs related to the building where the manufacturing takes place. The space takes into account the number of parallel processes as well as the blade size. First, for each operation, an estimate of the floor space is computed.

For the material cutting, industrial experience suggests $3 \mathrm{~m}^{2}$ per meter of blade length:

$$
\text { Floor space }=3 \mathrm{~m}^{2} / \mathrm{m} * \text { Blade Length }
$$

For all other processes, the following equation is adopted: 


$$
\text { Floor space }=\# \text { Processes } *\left(\Delta+L_{1}\right) *\left(\Delta+L_{2}\right)
$$

where $\Delta$ is the space needed between parts (the default is assumed equal to 2 meters) and $L_{1}$ and $L_{2}$ are the main dimensions of each part. Table 19 summarizes the lengths assumed in each process. Notably, some processes run with the chord line parallel to the ground and therefore require space for the whole chord width, while in many other the blade is pitched (rotated about its pitch axis) by 90 degrees, so the floor space required is only a portion of the chord width.

Table 19. Lengths $L_{1}$ and $L_{2}$ Used to Compute the Floor Space Needed in each Operation

\begin{tabular}{lcc}
\hline & $L_{1}$ & $L_{2}$ \\
\hline Infusion root preform lp & Root length & Root diameter \\
Infusion root preform hp & Root length & Root diameter \\
Infusion webs (per web) & Length web & Width web \\
Infusion spar caps lp & Length spar cap & Width spar cap \\
Infusion spar caps hp & Length spar cap & Width spar cap \\
Infusion skin shell lp & Length blade & Max chord \\
Infusion skin shell hp & Length blade & Max chord \\
Trim & Length blade & Max chord \\
Overlay & Length blade & Root diameter \\
Postcure & Length blade & Root diameter \\
Root cut and drill & Length blade & Max chord \\
Root hardware install & Length blade & Root diameter \\
Surface preparation & Length blade & Root diameter \\
Paint & Length blade & Root diameter \\
Surface inspection and finish & Length blade & Root diameter \\
Weight and balance & Length blade & Root diameter \\
Inspection & Length blade & Root diameter \\
Shipping preparation & Length blade & Root diameter \\
\hline
\end{tabular}

The building capital cost investment is then computed assuming a constant cost per square meter, whose default value is $\$ 800 / \mathrm{m}^{2}$ :

Building Investment $=$ Floor Space $*$ Floor Cost

Finally, the cost per blade related to the factory building is equal to:

$$
\text { Building Costs }=\frac{\text { Building Investment }}{\text { Building Life } * \text { \# Blades per Year }}
$$

The building life is assumed equal to 30 years to amortize the up-front investment. 


\subsection{Utility Costs}

Utility costs are assumed to be the costs connected to the use of electricity during each process. An average power consumption for each $\mathrm{m}^{2}$ of floor space is first estimated for each process. This consists of an average power consumption of $250 \mathrm{~kW} / \mathrm{m}^{2}$ :

$$
\text { Power Consumption }=\frac{\text { Floor Space } * 250 \mathrm{~kW} / \mathrm{m}^{2}}{\text { Production Days } * 24 \mathrm{hr}}
$$

The default assumed for the production days is 250 per year, as discussed at the beginning of Section 4.

Separate energy uses are estimated for the processes that involve curing of the composite matrix. These add to the baseline energy an amount of heat that is proportional to the component mass.

$$
\text { Additional Power Consumption }=\# \text { Processes } * \text { Mass Comp. } * \text { kJperkg }
$$

$k J$ perkg is the amount of power needed to run the heated molds and the postcuring oven.

$$
k J \text { perkg }=\frac{C_{p} *\left(T_{\text {cure }}-T_{\text {amb }}\right)}{\text { Time }_{\text {cure }} * \eta}
$$

Here these quantities are:

- $C_{p}: 1.018 \mathrm{~kJ} /(\mathrm{kgC})-$ Standard heat coefficient of composites

- $T_{\text {cure }}: 70$ degrees Celsius-Standard curing temperature of composites

- $T_{a m b}: 22$ degrees Celsius-Standard ambient temperature

- $\eta$ : 50\%-Standard efficiency of molds and industrial ovens

Once the power consumption is estimated for each process, the yearly cost for utilities is defined as the sum across all processes of:

$$
\text { Yearly Utility Costs }=\frac{\text { Price Electr. } * \text { Power Consumption } * C T}{(1-\text { Avg Downtime }) *(1-\text { Rejection Rate })}
$$

The utility cost split for each blade is:

$$
\text { Utility Costs }=\frac{\text { Yearly Utility Costs }}{\# \text { Blades per Year }}
$$

\subsection{Tooling Costs}

An important cost contribution comes from the investment on tooling (i.e., the molds used to infuse the various components). Molds are assumed to scale linearly with the area to be infused. The costs per blade are estimated as:

$$
\text { Tooling Investment }=\# \text { Processes } * \text { Tooling Costs per Area } * \text { Component Area }
$$




$$
\text { Tooling Costs }=\frac{\text { Tooling Investment }}{\text { Tooling Life } * \text { Blades per Year }}
$$

The default value of tooling cost per area is assumed equal to $\$ 5,000 / \mathrm{m}^{2}$. A productive life of 4 years is assumed for the molds.

\subsection{Equipment Costs}

The manufacturing of wind turbine blades requires tools and equipment for each different step. The costs for equipment are here computed as:

$$
\text { Equipment Investment }=\# \text { Processes } * \text { Equipment Costs per Length } * L
$$

$$
\text { Equipment Costs }=\frac{\text { Equipment Investment }}{\text { Equipment Life } * \# \text { Blades per Year }}
$$

The parameter $L$ varies from operation to operation. Default values of equipment cost per length have been defined based on the real equipment costs of a 61.5-meter-long blade, while the scaling parameters $L$ are assumed. Table 20 reports the values.

Table 20. Default Values of Equipment Cost per Length and Scaling Length, $L$, to Estimate the Total Equipment Cost per Blade

\begin{tabular}{lrl}
\hline & Cost $[\$ / \mathrm{m}]$ & Scaling length $(L)$ \\
\hline Cutting & 5,000 & Blade length \\
Infusion root preform lp & 15,000 & Root diameter \\
Infusion root preform hp & 15,000 & Root diameter \\
Infusion webs (per web) & 1,700 & Web length \\
Infusion spar caps lp & 1,700 & Spar cap length \\
Infusion spar caps hp & 1,700 & Spar cap length \\
Infusion skin shell lp & 1,600 & Spar cap length \\
Infusion skin shell hp & 1,600 & Spar cap length \\
Assembly & 6,600 & Total web length \\
Trim & 25,000 & Blade length \\
Overlay & 250 & Blade length \\
Postcure & 28,500 & Blade length \\
Root cut and drill & 390,000 & Root diameter \\
Root hardware install & 15,500 & Root diameter \\
Surface preparation & 160 & Blade outer surface \\
Paint & 57,000 & Blade length \\
Surface inspection and finish & 800 & Blade length \\
Weight and balance & 200,000 & Constant \\
Inspection & 400 & Blade length \\
Shipping preparation & 8,000 & Root diameter \\
\hline
\end{tabular}




\subsection{Maintenance Costs}

Buildings, tools, and equipment need regular maintenance. The cost per blade are here estimated as:

$$
\text { Maintenance Costs }=\frac{\text { Rate } *(\text { Investment Building }+ \text { Investment Tooling }+ \text { Investment Equipment })}{\text { \# Blades per Year }}
$$

A flat rate of $4 \%$ is assumed as the default value.

\subsection{Cost of Capital}

Finally, blade cost is influenced by the cost of capital. This model estimates the cost of capital per blade as the sum of the annuities of building, tooling, and equipment investments and the working annuity, which accounts for direct labor cost, overhead, and utilities.

The annuity is defined as the sum of the 12-month payments against a loan principal plus the interest. The model assumes a capital recovery rate of $10 \%$. For the working annuity, a working capital period, which is the amount of time it takes to turn the net current assets and current liabilities into cash, if 3 months is assumed.

The cost of capital is then obtained as:

$$
\text { Cost of Capital }=\frac{\text { Total Annuity }- \text { Total Costs per Year }}{\# \text { Blades per Year }}
$$




\section{Applications}

This section exercises the blade cost model to estimate the costs of three blades. The breakdown of variable and fixed costs is reported next.

\subsection{WindPACT Blade}

The Wind Partnership for Advanced Component Technologies (WindPACT) project ran in the early 2000s and aimed at identifying technological improvements that could enable the cost of energy from wind turbines to fall to a target of $\$ 3.0 / \mathrm{kWh}$ in low-wind-speed sites (Malcolm and Hansen 2006). During the project, a 1.5-MW wind turbine was developed, with 33.25-meter-long blades, each modeled here with a mass of 4,335.34 kg. The bill of materials, labor, and cycle time for the manufacturing of these conceptual blades are reported next.

\section{Bill of Materials}

The bill of materials of the 33.25-meter-long blade is reported in Table 21 and broken down in Figure 1. The bill of materials is dominated by the fabrics, and especially by the unidirectional glass-fiber of the spar caps. The epoxy resin, with $\$ 4,690.55$ also represents a main cost item. Finally, the blade root is modeled with 40 bolts, which together with the lightning protection system, adds $209 \mathrm{~kg}$ of metallic parts to the blade.

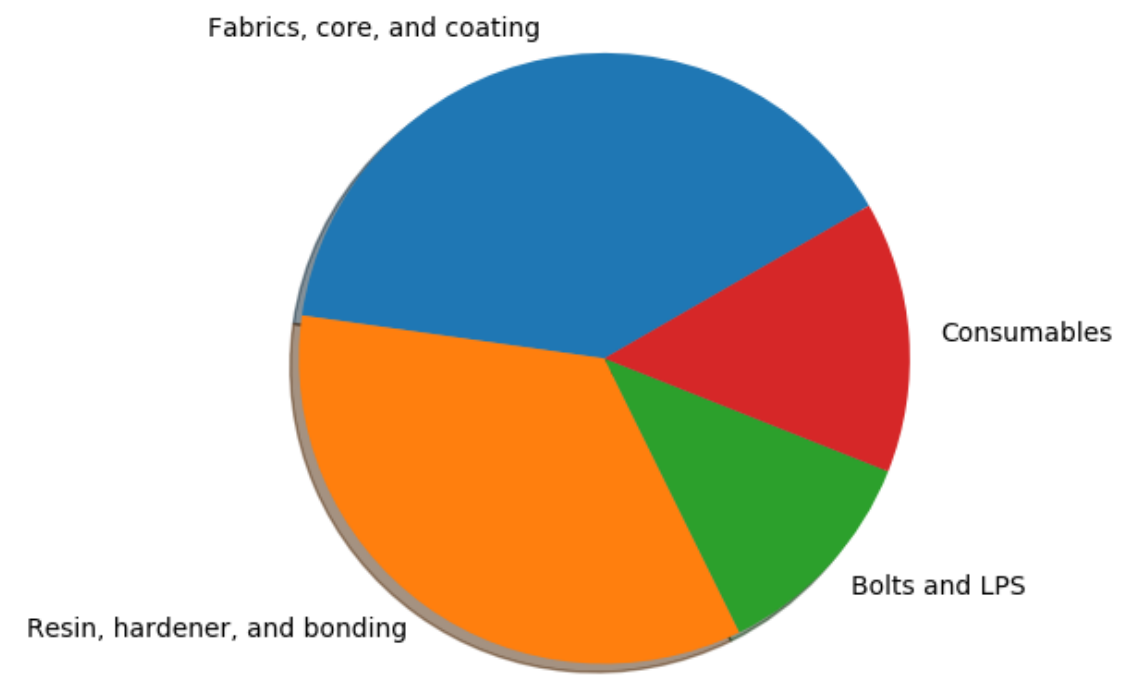

Figure 1. Shares of the Bill of Materials of the WindPACT Blade

\section{Labor and CT}

The labor and cycle time needed to manufacture the 33.25-meter-long blade is reported in Table 22. The number of labor hours required to complete the whole manufacturing process is estimated at 407 , while, as per assumption, 
Table 21. Bill of Materials of the WindPACT Blade

\begin{tabular}{lrlrlrl}
\hline $\begin{array}{l}\text { Composites } \\
\text { and filler }\end{array}$ & $\begin{array}{c}\text { Cost with } \\
\text { waste }[\$]\end{array}$ & $\begin{array}{l}\text { Resin and } \\
\text { adhesive }\end{array}$ & $\begin{array}{r}\text { Cost with } \\
\text { waste }[\$]\end{array}$ & $\begin{array}{l}\text { Other } \\
\text { parts }\end{array}$ & $\begin{array}{r}\text { Cost } \\
{[\$]}\end{array}$ \\
\hline Bx GF & 350.22 & Resin & $4,690.55$ & Bolts & 989.60 & \\
UD GF & $4,013.28$ & Hardener & $1,407.17$ & Barrel nuts & 475.01 & \\
Gelcoat & 812.14 & Adhesive Part A & $2,018.50$ & LPS & $1,405.60$ & \\
Tx GF & 546.00 & Adhesive Part B & 373.42 & Consumables & $3,530.67$ & \\
Balsa & $3,965.49$ & & & & & Total \\
& & & & & $6,400.88$ & $\mathbf{2 4 , 5 7 7 . 6 5}$ \\
\hline
\end{tabular}

the gating cycle time is 24 hours. The infusion of webs, spar caps, and skins are visibly the most labor-intensive processes. Teams of five workers are assumed for the infusion of LP and HP skins as well as for the assembly.

\section{Overall Blade Cost}

The final breakout of variable and fixed costs is reported in Table 23 and in Figure 2. Material and labor costs represent almost three-quarters of the blade total cost, which is estimated equal to $\$ 52,146.09$.

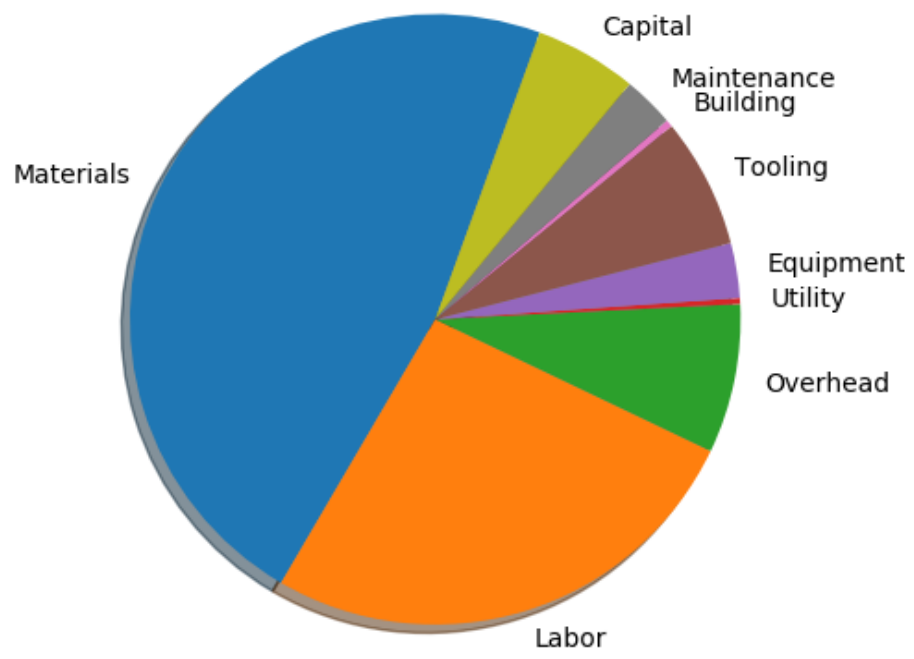

Figure 2. Shares of the Overall Costs of the WindPACT Blade 
Table 22. Labor and Cycle Time of the WindPACT Blade

\begin{tabular}{lccc}
\hline Operation & Labor [hour] & Skin Mold Gating CT [hour] & Nongating CT [hour] \\
\hline Material cutting & 2.50 & {$[-]$} & 0.85 \\
Root preform lp & 4.42 & {$[-]$} & 3.67 \\
Root preform hp & 4.42 & {$[-]$} & 3.67 \\
Infusion shear web number 1 & 22.11 & {$[-]$} & 4.73 \\
Infusion shear web number 2 & 22.32 & {$[-]$} & 4.76 \\
Infusion spar cap lp & 32.18 & {$[-]$} & 5.77 \\
Infusion spar cap hp & 32.18 & {$[-]$} & 5.77 \\
Lp skin & 63.81 & 15.57 & {$[-]$} \\
Hp skin & 63.36 & {$[-]$} & 15.57 \\
Assembly & 48.10 & 6.67 & {$[-]$} \\
Demolding & 3.67 & 1.75 & {$[-]$} \\
Trim & 9.65 & {$[-]$} & 2.11 \\
Overlay & 26.09 & {$[-]$} & 3.85 \\
Postcure & 1.42 & {$[-]$} & 9.58 \\
Root cut and drill & 6.78 & {$[-]$} & 3.31 \\
Root hardware installation & 4.13 & {$[-]$} & 1.98 \\
Surface preparation & 24.21 & {$[-]$} & 3.15 \\
Painting & 18.72 & {$[-]$} & 4.76 \\
Surface finishing & 5.11 & {$[-]$} & 1.76 \\
Weight balance & 5.67 & {$[-]$} & 2.75 \\
Final inspection & 1.40 & {$[-]$} & 0.53 \\
Shipping preparation & 5.13 & {$[-]$} & 2.31 \\
Total & $\mathbf{4 0 7 . 3 7}$ & $\mathbf{2 4 . 0 0}$ & $\mathbf{8 0 . 8 9}$ \\
\hline
\end{tabular}

Table 23. Total Costs of the WindPACT Blade

\begin{tabular}{lr}
\hline & Costs [\$] \\
\hline Material costs & $24,577.65$ \\
Labor costs & $13,727.60$ \\
Overhead labor costs & $4,118.28$ \\
Utility costs & 165.74 \\
Equipment costs & $1,518.38$ \\
Tooling costs & $3,590.40$ \\
Building costs & 197.44 \\
Maintenance costs & $1,418.74$ \\
Cost of capital & $2,831.86$ \\
\hline Variable & $38,470.99$ \\
Fixed & $13,675.10$ \\
\hline Total & $\mathbf{5 2 , 1 4 6 . 0 9}$ \\
\hline
\end{tabular}




\subsection{IEA Wind Task 37 Land-Based Reference Wind Turbine Blade}

Within the IEA Wind Task 37, two novel wind turbine models have been defined (Bortolotti et al. 2019). These aim at acting as references for future research projects on wind energy. Here, the blade of the land-based wind turbine model is used to exercise the cost model. The machine, which has been developed by the Technische Universität München and by NREL, mounts a 130-meter rotor diameter on a tower reaching 110 meters at hub height. The blade is modeled within RotorSE with a mass of $14,285 \mathrm{~kg}$ and three webs.

\section{Bill of Materials}

The bill of materials of the blade sums up to $\$ 73,638.82$. This value is mostly driven by the triaxial glass-fiber of the blade root and shell skin, by the unidirectional glass-fiber of the spar caps and finally by the epoxy resin. Table 24 and Figure 3 report the details of the bill of materials.

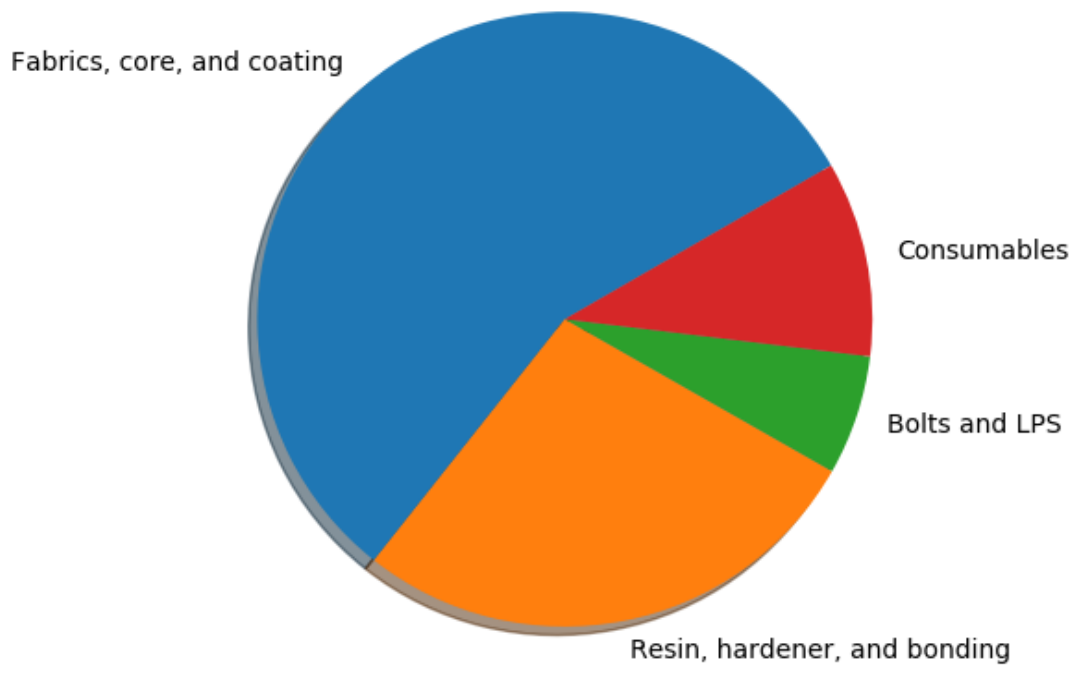

Figure 3. Shares of the Bill of Materials of the IEA Land-Based Reference Wind Turbine Blade

Table 24. Total Composite, Core, and Coating Costs of the IEA Land-Based Reference Wind Turbine Blade

\begin{tabular}{|c|c|c|c|c|c|c|}
\hline $\begin{array}{l}\text { Composites } \\
\text { and filler }\end{array}$ & $\begin{array}{c}\text { Cost with } \\
\text { waste [\$] }\end{array}$ & $\begin{array}{l}\text { Resin and } \\
\text { adhesive }\end{array}$ & $\begin{array}{l}\text { Cost with } \\
\text { waste [\$] }\end{array}$ & $\begin{array}{l}\text { Other } \\
\text { parts }\end{array}$ & $\begin{array}{r}\text { Cost } \\
{[\$]}\end{array}$ & \\
\hline $\mathrm{Bx}$ GF & 960.07 & Resin & $10,962.87$ & Bolts & $1,361.36$ & \\
\hline UD GF & $9,414.32$ & Hardener & $3,288.86$ & Barrel nuts & 653.45 & \\
\hline Tx GF & $13,783.83$ & Adhesive Part A & $5,010.74$ & LPS & $2,624.00$ & \\
\hline Balsa & $17,090.18$ & Adhesive Part B & 926.99 & Consumables & $7,562.14$ & \\
\hline Total & $41,248.41$ & Total & $20,189.46$ & Total & $12,200.95$ & $\begin{array}{r}\text { Total } \\
73,638.82\end{array}$ \\
\hline
\end{tabular}




\section{Labor and CT}

Similar to the WindPACT blade, the labor and cycle time model return the main infusions and the assembly as the most labor-intensive processes (Table 25). Here, teams formed of 19 and 18 workers are necessary to keep the gating cycle time at 24 hours. The total number of labor hours is estimated at 1,134, which aligns well with the indications provided by original equipment manufacturers.

Table 25. Labor and Cycle Time of the IEA Land-Based Reference Wind Turbine Blade

\begin{tabular}{lccc}
\hline Operation & Labor [hour] & Skin Mold Gating CT [hour] & Nongating CT [hour] \\
\hline Material cutting & 41.71 & {$[-]$} & 14.22 \\
Root preform lp & 10.74 & {$[-]$} & 7.10 \\
Root preform hp & 10.74 & {$[-]$} & 7.10 \\
Infusion shear web number 1 & 69.30 & {$[-]$} & 10.02 \\
Infusion shear web number 2 & 69.42 & {$[-]$} & 9.99 \\
Infusion shear web number 3 & 28.15 & {$[-]$} & 5.86 \\
Infusion spar cap lp & 59.75 & {$[-]$} & 9.07 \\
Infusion spar cap hp & 58.83 & {$[-]$} & 8.98 \\
Lp skin & 197.91 & 15.41 & {$[-]$} \\
Hp skin & 191.14 & {$[-]$} & 15.41 \\
Assembly & 186.23 & 6.60 & {$[-]$} \\
Demolding & 4.70 & 1.99 & {$[-]$} \\
Trim & 15.60 & {$[-]$} & 3.10 \\
Overlay & 53.14 & {$[-]$} & 6.52 \\
Postcure & 1.71 & {$[-]$} & 9.68 \\
Root cut and drill & 9.09 & {$[-]$} & 4.37 \\
Root hardware installation & 6.06 & {$[-]$} & 2.85 \\
Surface preparation & 68.38 & {$[-]$} & 8.67 \\
Painting & 23.14 & {$[-]$} & 5.87 \\
Surface finishing & 13.94 & {$[-]$} & 4.70 \\
Weight balance & 6.24 & {$[-]$} & 2.94 \\
Final inspection & 2.71 & {$[-]$} & 1.09 \\
Shipping preparation & 5.42 & {$[-]$} & 2.43 \\
Total & $\mathbf{1 1 3 4 . 0 5}$ & $\mathbf{2 4 . 0 0}$ & $\mathbf{1 3 9 . 9 8}$ \\
\hline
\end{tabular}

\section{Overall Blade Cost}

The total blade cost is estimated at $\$ 154,090.40$, with variable costs representing more than $70 \%$ of the total costs. Table 26 and Figure 4 show the detailed breakout of the total costs of the blade of the IEA land-based reference wind turbine. 
Table 26. Total Costs of the IEA Land-Based Reference Wind Turbine Blade

\begin{tabular}{lr}
\hline & Cost [\$] \\
\hline Material costs & $73,638.82$ \\
Labor costs & $38,314.44$ \\
Overhead labor costs & $11,494.33$ \\
Utility costs & 693.07 \\
Equipment costs & $4,347.16$ \\
Tooling costs & $11,854.42$ \\
Building costs & 651.54 \\
Maintenance costs & $4,417.42$ \\
Cost of capital & $8,679.20$ \\
\hline Variable & $112,646.33$ \\
Fixed & $41,444.07$ \\
\hline Total & $\mathbf{1 5 4 , 0 9 0 . 4 0}$ \\
\hline
\end{tabular}

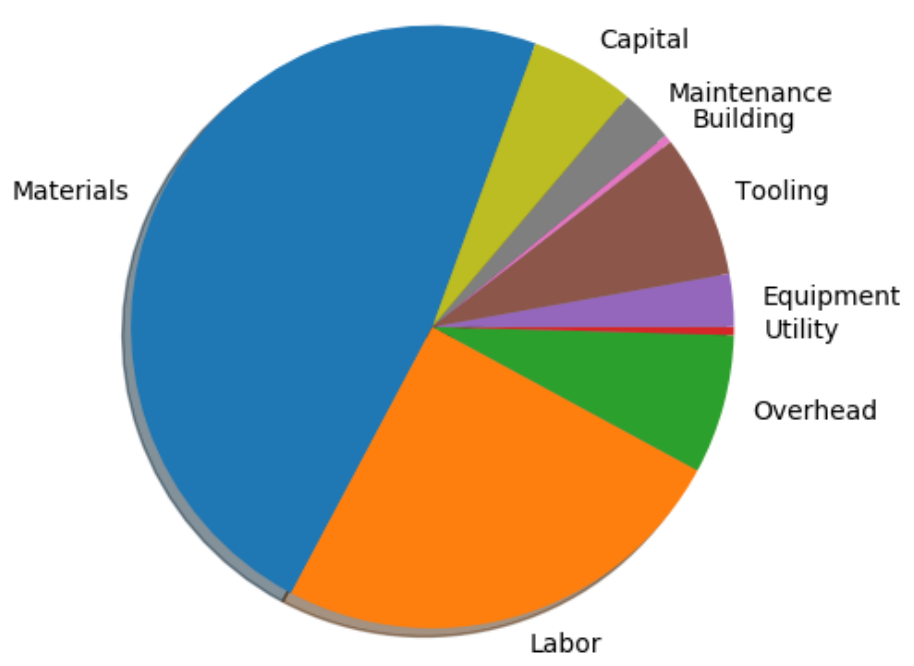

Figure 4. Shares of the Overall Costs of the IEA Land-Based Reference Wind Turbine Blade 


\subsection{SNL-100-03}

At Sandia National Laboratories, a large effort went into the design, definition, and testing of very large wind turbine blades (Griffith and Ashwill 2011; Griffith 2013; Griffith and Richards 2014). The latest blade model, which is called SNL-100-03 and which adopts flatback airfoils and carbon-fiber spar caps (Griffith and Richards 2014), is here used to exercise the blade cost model. The design of the SNL-100-03 blade is the lightest of all SNL blades, with RotorSE computing a total blade mass of $49,977 \mathrm{~kg}$.

\section{Bill of Materials}

The carbon-fiber in the spar caps of the SNL-100-03 increases the cost related to fabrics in the bill of materials both from an absolute and a relative perspective compared to glass-fiber-only blades. Table 27 and Figure 5 report the details of the bill of materials.

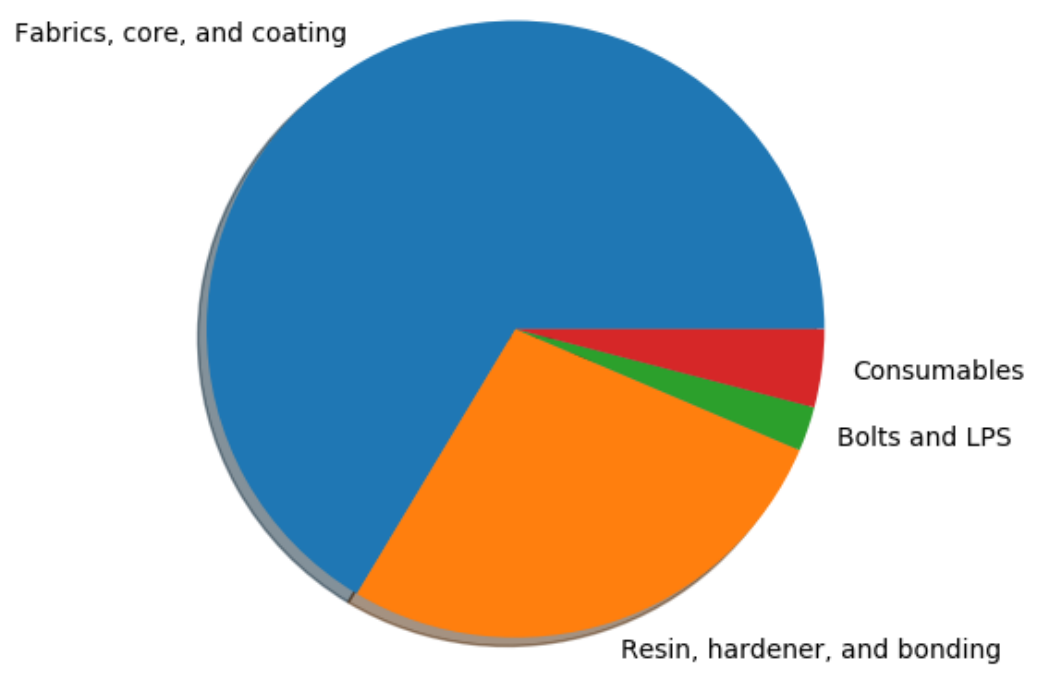

Figure 5. Bill of Materials of the SNL-100-03 Blade

Table 27. Total Composite, Core, and Coating Costs of the SNL-100-03 Blade

\begin{tabular}{lrlrlrl}
\hline $\begin{array}{l}\text { Composites } \\
\text { and filler }\end{array}$ & $\begin{array}{r}\text { Cost with } \\
\text { waste }[\$]\end{array}$ & $\begin{array}{l}\text { Resin and } \\
\text { adhesive }\end{array}$ & $\begin{array}{r}\text { Cost with } \\
\text { waste }[\$]\end{array}$ & $\begin{array}{l}\text { Other } \\
\text { parts }\end{array}$ & $\begin{array}{r}\text { Cost } \\
{[\$]}\end{array}$ \\
\hline Bx GF & $7,370.97$ & Resin & $63,027.83$ & Bolts & $2,356.19$ & \\
UD CF & $79,045.98$ & Hardener & $18,899.57$ & Barrel nuts & $1,130.97$ & \\
UD GF & $7,214.01$ & Adhesive Part A & $7,830.56$ & LPS & $4,180.00$ & \\
Tx GF & $45,990.11$ & Adhesive Part B & $1,448.65$ & Consumables & $13,449.65$ & \\
Gelcoat & $5,924.00$ & & & & & \\
Balsa & $19,770.06$ & & & & & Total \\
Foam & $49,737.08$ & & & & $21,116.81$ & $\mathbf{3 2 7 , 3 7 5 . 6 3}$ \\
Total & $215,052.21$ & Total & $91,206.61$ & Total & & \\
\hline
\end{tabular}




\section{Labor and Cycle Time}

As with the other two blades, the labor and cycle time model return the main infusions and the assembly as the most labor-intensive processes; see Table 28. To manufacture the SNL-100-03 blade, 2,654 labor hours are required. To limit gating cycle time within the 24 hours, very large teams formed of 58 and 36 workers are estimated to be employed in the infusion of skins and assembly, respectively. These numbers may actually be suboptimal and an interesting factory management problem would consist of an optimization between cycle time and team size.

Table 28. Labor and Cycle Time of the SNL-100-03 Blade

\begin{tabular}{lccc}
\hline Operation & Labor [hour] & Skin Mold Gating CT [hour] & Nongating CT [hour] \\
\hline Material cutting & 136.10 & {$[-]$} & 47.57 \\
Root preform lp & 16.64 & {$[-]$} & 10.42 \\
Root preform hp & 16.64 & {$[-]$} & 10.42 \\
Infusion shear web number 1 & 155.97 & {$[-]$} & 19.27 \\
Infusion shear web number 2 & 152.32 & {$[-]$} & 18.91 \\
Infusion shear web number 3 & 69.18 & {$[-]$} & 10.12 \\
Infusion shear web number 4 & 24.48 & {$[-]$} & 5.45 \\
Infusion spar cap lp & 152.87 & {$[-]$} & 19.51 \\
Infusion spar cap hp & 152.87 & {$[-]$} & 19.51 \\
Lp skin & 484.73 & 14.76 & {$[-]$} \\
Hp skin & 478.77 & {$[-]$} & 14.76 \\
Assembly & 443.55 & 6.33 & {$[-]$} \\
Demolding & 9.23 & 2.92 & {$[-]$} \\
Trim & 23.00 & {$[-]$} & 4.33 \\
Overlay & 86.99 & {$[-]$} & 9.91 \\
Postcure & 2.17 & {$[-]$} & 9.84 \\
Root cut and drill & 14.65 & {$[-]$} & 6.99 \\
Root hardware installation & 10.63 & {$[-]$} & 4.98 \\
Surface preparation & 145.22 & {$[-]$} & 18.28 \\
Painting & 30.82 & {$[-]$} & 7.79 \\
Surface finishing & 29.31 & {$[-]$} & 9.83 \\
Weight balance & 7.16 & {$[-]$} & 3.25 \\
Final inspection & 4.91 & {$[-]$} & 2.04 \\
Shipping preparation & 6.21 & {$[-]$} & 2.75 \\
Total & $\mathbf{2 6 5 4 . 4 6}$ & $\mathbf{2 4 . 0 0}$ & $\mathbf{2 5 5 . 9 3}$ \\
\hline
\end{tabular}

\section{Overall Blade Cost}

The overall blade cost is estimated to be $\$ 547,723.35$. The details of variable and fixed costs are reported in Table 29 and Figure 6. Notably, the use of carbon-fiber increases the share of cost of the materials, here representing $60 \%$ of the blade total costs. 
Table 29. Total Costs of the SNL-100-03 Blade

\begin{tabular}{lr}
\hline & Cost [\$] \\
\hline Material cost & $327,375.64$ \\
Labor cost & $89,825.28$ \\
Overhead labor cost & $26,947.58$ \\
Utility cost & $3,090.84$ \\
Equipment cost & $12,705.90$ \\
Tooling cost & $39,683.74$ \\
Building cost & $2,951.68$ \\
Maintenance cost & $14,973.77$ \\
Cost of capital & $30,168.92$ \\
\hline Variable & $420,291.76$ \\
Fixed & $127,431.59$ \\
\hline Total & $\mathbf{5 4 7 , 7 2 3 . 3 5}$ \\
\hline
\end{tabular}

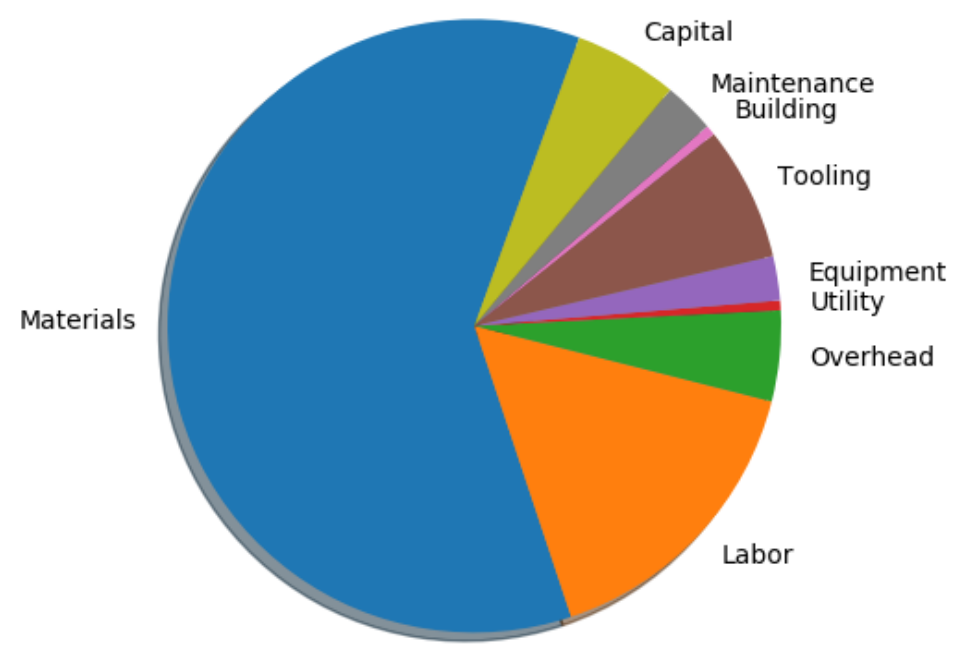

Figure 6. Shares of the Overall Costs of the SNL-100-03 Blade 


\section{Conclusions and Outlook on Future Work}

A model to estimate the cost of wind turbine blades has been developed and is described in this document. The model first estimates the bill of materials, then the labor and cycle time required for a vacuum assisted resin transfer molding process. This data is used to construct a virtual model of a blade factory. With it, the costs per blade for labor, utilities, building, tooling, equipment, maintenance, overhead, and capital are computed. The model is implemented within WISDEM, the multidisciplinary analysis and design optimization framework developed at NREL. The model is tested on three wind turbine blades of $33 \mathrm{~m}, 63 \mathrm{~m}$ and $100 \mathrm{~m}$ in length.

In the future, a validation process with detailed industrial data should challenge all model assumptions and help tune the model. So far, the model fits well within the trends for bill of materials, labor hours, and total blade costs shared by blade manufacturers who helped develop this model.

The model should also be subject of improvements in several areas. To start, the price of foam and balsa wood has so far been assumed proportional to the area, while it is in reality also proportional to the thickness. The list of consumables may also be extended, for example, with materials adopted during the finishing operations. Additionally, the model should support blade components manufactured via methods alternative to VARTM, such as pultrusion, and should be able to estimate the costs of bonded root inserts, which are more and more commonly used, as well as segmented blades. A step of ultrasonic inspection could also be added. This is often performed on the bonding lines and should be part of the labor model as well as of the equipment. Similarly, a step for remediation could be added to the labor model. Finally, the virtual model of the factory could be made more sophisticated, first by allowing the cycle time to exceed 24 hours and estimating the consequences, and later to model and optimize teams of varying size. 


\section{Bibliography}

Anon. 2018. Bureau Labor of Statistics. Accessed October 10, 2018: https://www.bls.gov/news.release/ecec.nr0.htm. Bortolotti, P., et al. 2019. IEA Wind Task 37 on System Engineering in Wind Energy WP2.1 Reference Wind Turbines. Tech. rep. International Energy Agency Wind Task 37.

Dykes, K., et al. 2014. Sensitivity analysis of wind plant performance to key turbine design parameters: a systems engineering approach. Tech. rep. National Renewable Energy Laboratory.

Griffith, D. T. 2013. The SNL100-01 Blade: Carbon Design Studies for the Sandia 100-meter Blade. Tech. rep. Sandia National Laboratories.

Griffith, D. T., and T. D. Ashwill. 2011. The Sandia 100-meter All-glass Baseline Wind Turbine Blade: SNL100-00. Tech. rep. Sandia National Laboratories.

Griffith, D. T., and P. W. Richards. 2014. The SNL100-03 Blade: Design Studies with Flatback Airfoils for the Sandia 100-meter Blade. Tech. rep. Sandia National Laboratories.

Malcolm, D. J., and A. C. Hansen. 2006. WindPACT Turbine Rotor Design Study. Tech. rep. National Renewable Energy Laboratory. 